\title{
Rating-based CDS curves
}

\section{Olga Kolokolova, Ming-Tsung Lin \& Ser-Huang Poon}

To cite this article: Olga Kolokolova, Ming-Tsung Lin \& Ser-Huang Poon (2018): Rating-based CDS curves, The European Journal of Finance, DOI: 10.1080/1351847X.2018.1511441

To link to this article: https://doi.org/10.1080/1351847X.2018.1511441

\section{央 Published online: 29 Aug 2018.}

Submit your article to this journal $\pi$

$$
\text { Џll Article views: } 1
$$




\title{
Rating-based CDS curves
}

\author{
Olga Kolokolova ${ }^{a}$, Ming-Tsung Lin ${ }^{b}$ and Ser-Huang Poon ${ }^{a}$ \\ ${ }^{a}$ Alliance Manchester Business School, University of Manchester, Manchester, UK; ${ }^{b}$ Department of Accounting and Finance, De \\ Montfort University, Leicester, UK
}

\begin{abstract}
This paper explores the extent to which term structure of individual credit default swap (CDS) spreads can be explained by the firm's rating. Using the Nelson-Siegel model, we construct, for each day, CDS curves from a cross-section of CDS spreads for each rating class. We find that individual CDS deviations from the curve tend to diminish over time and CDS spreads converge towards the fitted curves. The likelihood of convergence increases with the absolute size of the deviation. The convergence is especially stable if CDS spreads are lower relative to the rating-based curve. Trading strategies exploiting the convergence generate an average return of 3.7\% (5-day holding period) and $9 \%$ (20-day holding period).
\end{abstract}

\section{ARTICLE HISTORY}

Received 22 September 2017 Accepted 9 August 2018

\section{KEYWORDS}

Credit default swap; trading strategy; CDS term structure; credit rating

JEL

G11; G17; G24

\section{Introduction}

The outstanding notional value of CDS (credit default swap) contracts is multi-trillion dollars, and identifying the determinants of CDS spreads has been a central question in CDS studies. Recently, the CDS market has become active again after the market shrunk during the financial turbulence in 2007-2009. \$15.7 billion notional positions of single-name CDSs were cleared in the Intercontinental Exchange in January 2017. ${ }^{1}$

The pricing for CDSs, conventionally, is based on evaluating individual firms' credit/default risk, as the contract is meant as a protection against a firm's default. In theory, the price of a CDS should be driven only by a firm's default probability and the recovery rate. ${ }^{2}$ Empirically, however, other non-credit factors also affect CDS spreads. Hull and White (2001) include counterparty default risk in pricing CDS spreads. The CDS illiquidity affects CDS spreads profoundly (see Corò, Dufour, and Varotto 2013; Qiu and Yu 2012; Tang and Yan 2007). Several studies find that CDS spreads co-move systematically (see Anderson 2017; Galil et al. 2014).

One way to look at a systematic component of an individual firm's credit risk is to consider its credit rating, provided by one of the rating agencies (e.g. S\&P and Moody's). The rating can be linked to the average historical default probability of firms with similar credit conditions. Several studies, for example, Chava, Ganduri, and Ornthanalai (2016) and Hart and Zingales (2011), argue, however, that ratings are not very informative in terms of credit quality of a firm because they reflect past information. Others, such as Loeffler (2007) and Loeffler (2013), on the contrary, show that credit ratings can 'look through the cycle' and influence the short-term risk estimates. At the same time, a firm's default risk is relatively stable (Bai and Wu 2016), and it is still very common for market participants to use rating information to gauge the default risk. ${ }^{3}$

In this paper we show that a firm's rating also plays a role in determining CDS spreads. In particular, we provide a novel insight into the dynamics of individual CDS spreads. Our findings suggest that CDS market participants anchor a firm's CDS spread to other peer firms' CDS spreads with the same rating. Such anchoring affects not only the actual levels of CDS spreads but also their dynamics over time.

Methodologically, we group CDSs cross-sectionally by their underlying firm rating, and use a model of Nelson and Siegel (1987) to construct rating-based hazard rate curves. The use of a credit or rating curve is a common 
industrial practice, ${ }^{4}$ and the application of the Nelson-Siegel model is widely used in Treasury bond pricing. We are the first, to the best of our knowledge, to study the information content and time-series properties of ratingbased CDS curves. Using panel regressions in the spirit of the error correction model, we find that deviations of individual CDS-implied hazard rates from the rating curves move in the opposite direction to the time-series changes of the CDS-implied hazard rates, showing that the hazard rates (and, thus, CDS spreads themselves) converge to the rating-based fitted curves over time. Our findings suggest that the residuals are transient, while the fitted curves reflect market consensus on the fundamental non-diversifiable CDS risks.

Further analysis reveals that the convergence speed of CDS-implied hazard rates to the fitted curves is related to the magnitude of the deviation between them. We sort the CDSs into five portfolios based on the relative size of the deviations, and find evidence that larger deviations make convergence more likely. A trading strategy that consists of a long position in the portfolio of CDSs with the largest negative deviations and a short position in the portfolio of CDSs with the largest positive deviations produces statistically significant positive returns for 5 and 20 days holding periods. These results further confirm the time-series convergence of the CDS spreads to the rating-based CDS curves. Notably, the convergence speed of the portfolio containing strongly underpriced CDSs is less volatile over time and across ratings, CDS maturities, and industries than the convergence speed of the portfolio of overprices CDSs. This suggests that investors, in particular protection sellers, are more concerned about underestimating default risk than about being too conservative in their estimates, and almost always adjust relatively low CDS spreads towards a higher rating-implied level. Consequently, betting on the spread increase of relatively underpriced CDS contracts consistently deliveries positive and significant average returns, even after adjusting for transaction costs. Our results are robust across different years, industries, rating classes and CDS maturities, highlighting the overall importance of the rating classification for investors' decisions in the CDS market.

\section{Related literature}

Our study is related to several strands of literature: the first one illustrates the links between credit ratings and individual CDS spreads, the second one highlights the importance of systematic drivers of CDS spreads, in addition to individual credit-risk-related variables, and the last one links through-the-cycle and point-in-time default risk estimation. ${ }^{5}$

Most of studies agree that there is a strong link between CDS spreads and credit ratings. The existing evidence on the direction of that link is, however, rather mixed. Some scholars suggest that CDS spread changes lead the announcements of rating changes, thus, ratings are less informative in the presence of traded CDSs (Chava, Ganduri, and Ornthanalai 2016; Finnerty, Miller, and Chen 2013; Hart and Zingales 2011). Others, on the contrary, document that rating announcements do impact CDS spreads. For example, Hull, Predescu, and White (2004) find that 'Review on Downgrade' announcements affect CDS spreads, and Norden and Weber (2004) and Micu, Remolona, and Wooldridge (2006) conclude that all types of rating announcements have a significant impact on CDS spreads.

As far as systematic factors are concerned, Longstaff et al. (2011) find that global factors are more important than individual country factors in driving sovereign CDS spreads. Doshi et al. (2013) show that variables reflecting market conditions, such as the 6-month Treasury yield and the difference between the 10-year and 6-month yields, can explain the cross-sectional CDS variations. Similarly, Tang and Yan (2013) study CDS transaction data and find both firm and market fundamental variables, such as VIX, are significant drivers of CDS spreads. The importance of macro variables also increases during the crisis period. Conrad, Dittmar, and Hameed (2011) show that changes of CDS spreads of systematically important financial institutions lead changes of CDS spreads of the other firms. Galil et al. (2014) find that median CDS spreads of mixed credit quality have a cross-sectional explanatory power for individual CDS spreads. Lin, Kolokolova, and Poon (2016) construct various CDS-based systematic factors, and show that these factors have a higher explanatory power for quarterly changes of 1-year CDS spreads than firm-specific factors.

Our study is linked to the strand of literature discussing differences and co-dependencies between the through-the-cycle and point-in-time default risk measures. Through-the-cycle approach captures 'permanent' credit risk; and the ratings reported by the rating agencies are the examples of such measures. The point-in-time 
approach also evaluates the current conditions and 'temporary' credit risk. A typical example here is Expected Default Frequencies (EDFs) used by Moody's KMV, which are based on firms' current firm market values and can timely capture the changes in credit quality. Although point-in-time methodology provides timely estimates for firm's credit risk, for practical purposes investors often need to have a more 'stable' version of credit risk estimation to trigger adjustments in their portfolios, in order to avoid unnecessary transaction costs (Altman 2004; Loeffler 2004). In Loeffler $(2004,2007,2013)$, the author conducts a series of studies for predictability on the default risk using ratings, and finds that the reported rating predicts the trends in the EDFs, estimated from various models such as Hodrick-Prescott filter and moving average. The author also argues that rating information is of the same level of importance as other market-based information for predicting firm's credit risk.

Our study suggests that credit ratings and rating-based hazard rate curves can be viewed as systematic determinants of individual CDS spreads, capturing the through-the-cycle credit risk of underlying bonds. Individual CDS spreads are influenced in addition by current conditions and the point-in-time creditworthiness of the underlying, which is reflected in their pricing. We provide empirical evidence that deviations from the rating-based curves disappear over time and CDS spreads converge towards the rating-based curves.

\section{Constructing rating-based CDS curves}

In this section, we first explain how the CDS-implied hazard rate is calculated from CDS spread. Then, we detail the Nelson-Siegel model and explain how it is used to produce the rating-based CDS curves.

CDS represents an insurance to protect CDS buyers against a loss due to the firm's default. In a CDS contract, protection sellers compensate protection buyers the amount lost due to a credit event (e.g. default). In return, protection buyers pay periodic premiums to protection sellers during the protection periods up to the credit event. Hence, the pricing of a CDS contract has two components: the protection part and the premium part.

Assume that there are $N$ payments in a CDS contract and the $N$ payment periods are $\left[t, t_{1}\right],\left[t_{1}, t_{2}\right], \ldots,\left[t_{N-1}\right.$, $\left.t_{N}\right]$. A premium is paid at the end of each period, and default takes place only immediately after the premium is paid such that there is no accrual at default. If the market discount rate $(r)$ and the firm's hazard rate (h) are time-varying, then the expected present values of the protection and premium legs at time $t$ can be expressed as ${ }^{6}$ :

$$
\begin{gathered}
\operatorname{PV}_{\text {Protection }}=\mathbb{E}\left[\sum_{i=1}^{N} \exp \left(-\int_{t}^{t_{i}} r_{u} \mathrm{~d} u\right) \exp \left(-\int_{t}^{t_{i}} h_{u} \mathrm{~d} u\right)(1-R) h_{t_{i}} \Delta t_{i} \mid \mathcal{F}_{t}\right], \\
P V_{\text {Premium }}=\mathbb{E}\left[\sum_{i=1}^{N} \exp \left(-\int_{t}^{t_{i}} r_{u} \mathrm{~d} u\right) \exp \left(-\int_{t}^{t_{i}} h_{u} \mathrm{~d} u\right) k \Delta t_{i} \mid \mathcal{F}_{t}\right],
\end{gathered}
$$

where $\Delta t_{i}$ is the time period between payments, $R$ is the recovery rate of the underlying CDS, $k$ is the premium (i.e. CDS spreads) paid by the protection buyer to the protection seller, and $\mathcal{F}$ is the information filtration. The fair price of the CDS spread $(k)$ is determined when the two expected present values are the same. Our aim is to obtain $h_{u}$ implied by the observed CDS spread.

Following Carr and $\mathrm{Wu}$ (2011), for each CDS spread of a particular maturity $\tau$ we assume a flat term structure for the market discount rate and the hazard rate such that $r_{u}=r$ and $h_{u}=h$. Then, under no-arbitrage,

$$
\mathrm{e}^{-r\left(t_{i}-t\right)} \mathrm{e}^{-h\left(t_{i}-t\right)}(1-R) h \Delta t_{i}=\mathrm{e}^{-r\left(t_{i}-t\right)} \mathrm{e}^{-h\left(t_{i}-t\right)} k \Delta t_{i}, \quad \forall t_{i}
$$

Given the recovery rate $(R)$ and the CDS spread $(k)$, the hazard rate $h$ implied by a CDS spread is

$$
h=\frac{k}{1-R} .
$$

The resulting hazard rates are different for CDSs with different maturities; thus the CDS-implied hazard rate of firm $i$ at time $t$ with CDS maturity $\tau$ is expressed by $h_{i, t, \tau}=k_{i, t, \tau} /\left(1-R_{i, t}\right)$, where $R_{i, t}$ is the reported recovery 
rate in Markit. ${ }^{7}$ Thus, such hazard rates capture average default risk of the underlying bond over the lifetime of the CDS analogous to the yields to maturity of corporate bonds. ${ }^{8}$

We assign to each hazard rate the corresponding firm's average credit rating, which is also provided by Markit. Markit calculates a firm's average rating as the average of the Moody's and S\&P ratings adjusted to the seniority of the CDS and rounded to eliminate the ' + ' and '-' levels. The rating provides information about the comparative default risk across rating classes, assuming that all entities in the same rating class will have the same default rate. We then decompose the implied hazard rate $h_{i, t, \tau}$ into:

$$
h_{i, t, \tau}=y_{r, t, \tau}+e_{i, t, \tau}
$$

where $y_{r, t, \tau}$ is the hazard rate specific to rating class $r$ on day $t$ for maturity $\tau$, and $e$ is the firm-specific residual. $y_{r, t, \tau}$ is time-varying and maturity dependent, but the same for all firms in the same rating class; $y$ captures the systematic rating class information, while $e$ represents the firm's idiosyncratic information and noise.

The crucial question is then how to estimate the systematic rating class component. One may consider a simple approach of taking a mean or median across the implied hazard rates for each rating class. Such an approach, however, is likely to produce unstable results for ratings and tenors with low number of observations and to be extremely sensitive to outliers, which are often observed in the relatively illiquid CDS market due to its OTC nature. Thus, the resulting hazard rate curves are not likely to be smooth, and will be extremely volatile over time. Also, this simple approach does not account for the term structure of CDS tenors.

In order to overcome these issues, we use the information of the implied hazard rates for CDSs of different maturities jointly, when recovering the rating curves. In particular, we use the Nelson-Siegel model to estimate $y(\tau)$ for each rating class $r$ on day $t:^{9}$

$$
\begin{aligned}
y\left(\tau \mid \beta_{0}, \beta_{1}, \beta_{2}, m\right)= & \beta_{0}+\beta_{1}\left(\frac{1-\exp (-\tau / m)}{\tau / m}\right) \\
& +\beta_{2}\left(\frac{1-\exp (-\tau / m)}{\tau / m}-\exp (-\tau / m)\right),
\end{aligned}
$$

where $\beta_{0}$ and $\beta_{1}$ are the long-term and short-term hazard rates, $\beta_{2}$ captures a possible hump at the medium term, and $m$ determines the shape and the timing of the hump. Following $\mathrm{Hu}, \mathrm{Pan}$, and Wang (2013), among many others, we set $\beta_{0}>0, \beta_{0}+\beta_{1}>0$, and $m>0$ to avoid negative $y(\tau)$.

The estimation is performed for each observation date $t$, using all CDSs of the same rating $r$ on that day. Since $y(\tau)$ is fitted to a group of CDSs with the same rating, $y(\tau)$ will be the same for all CDSs that have the same maturity and the same rating. We do not impose any restrictions on the relation between CDS curves for different rating classes. The ratings provided by rating agencies do not change as frequently as CDS spreads. Therefore, it is not uncommon that a CDS spread with a better rating of the underlying is higher than a CDS spreads with a worse rating of the underlying. Such situations may lead to crossing of the estimated rating-based hazard rate curves. The shape of the fitted curves also reflects the investor preference for short-term or longterm CDS contracts at a given point in time, and contract liquidity may play a role too. Potential crossing of the curves, however, does not necessarily imply the existence of practically exploitable arbitrage opportunities, due to high transaction costs and the OTC structure of the market.

\section{Data}

The CDS spreads are collected from the Markit database for U.S. firms that are written on their senior unsecured debts. Our CDS sample is from May 2002 to May 2012. We exclude CDSs with default rating because there are too few observations, not enough for an adequate Nelson-Siegel fit. The time to maturity of the CDSs ranges from 6 months to 10 years. ${ }^{10}$ Markit reports composite CDS prices, which are the average prices for a given CDS as provided on that day by different contributors. When computing composite prices, Markit performs several checks related to the data quality, to make sure that the market value of the contracts is correctly reflected. For example, Markit tries to eliminate any bias in CDS spreads that may be due to the staleness of reported prices 
Table 1. Sample firm distribution.

\begin{tabular}{|c|c|c|c|c|c|c|c|c|}
\hline Industry & \#Firms & Percentage & Maturity & \#Firms & Percentage & Rating & \#Firms & Percentage \\
\hline Basic materials & 34 & 7.89 & 6-month & 344 & 79.81 & AAA & 3 & 0.70 \\
\hline Consumer goods & 76 & 17.63 & 1-year & 388 & 90.02 & $\mathrm{AA}$ & 11 & 2.55 \\
\hline Consumer services & 73 & 16.94 & 2-year & 383 & 88.86 & A & 74 & 17.17 \\
\hline Energy & 44 & 10.21 & 3-year & 402 & 93.27 & BBB & 167 & 38.75 \\
\hline Financials & 7 & 1.62 & 4-year & 351 & 81.44 & $\mathrm{BB}$ & 85 & 19.72 \\
\hline Healthcare & 38 & 8.82 & 5-year & 429 & 99.54 & B & 73 & 16.94 \\
\hline Industrials & 62 & 14.39 & 7-year & 401 & 93.04 & C & 20 & 4.64 \\
\hline Technology & 42 & 9.74 & 10-year & 395 & 91.65 & & & \\
\hline Telecommunications services & 13 & 3.02 & & & & & & \\
\hline Utilities & 31 & 7.19 & & & & & & \\
\hline Other & 11 & 2.55 & & & & & & \\
\hline Total & 431 & 100.00 & & & & & & \\
\hline
\end{tabular}

Notes: The table reports the number and percentage of firms in our sample having different rating classes, belonging to different industries, and having CDSs with different maturities from May 2002 to May 2012. The total number of firms with different ratings is different form the total number of firms with different industry classification, due to the fact that some firms have change their rating class during our sample.

Table 2. CDS descriptive statistics.

\begin{tabular}{|c|c|c|c|c|c|c|c|c|c|}
\hline \multicolumn{10}{|c|}{ Panel A: full sample period } \\
\hline & All & 6-month & 1-year & 2-year & 3-year & 4-year & 5-year & 7-year & 10-year \\
\hline Mean & 150.51 & 93.50 & 109.65 & 126.23 & 143.17 & 169.99 & 173.65 & 179.17 & 186.55 \\
\hline Std & 314.29 & 311.06 & 358.90 & 336.07 & 312.24 & 340.50 & 296.33 & 283.21 & 266.02 \\
\hline Max & $24,559.17$ & $14,652.77$ & $24,559.17$ & $11,462.29$ & $10,637.10$ & $10,120.71$ & $10,291.38$ & $9,980.42$ & $9,643.90$ \\
\hline Min & 0.60 & 0.60 & 0.81 & 0.79 & 1.28 & 1.45 & 2.33 & 3.27 & 4.34 \\
\hline$\#$ Obs & $3,658,096$ & 308,245 & 468,378 & 471,722 & 506,898 & 359,003 & 544,392 & 504,271 & 495,187 \\
\hline \multicolumn{10}{|c|}{ Panel B: rating class averages } \\
\hline & 6-month & 1-year & 2-year & & 3-year & 4-year & 5-year & 7-year & 10-year \\
\hline AAA & 11.88 & 11.98 & 16.21 & & 19.74 & 24.07 & 26.29 & 31.54 & 36.46 \\
\hline $\mathrm{AA}$ & 22.40 & 20.81 & 24.66 & & 27.42 & 36.66 & 35.16 & 40.60 & 45.60 \\
\hline A & 24.53 & 31.48 & 37.08 & & 44.89 & 51.19 & 58.38 & 65.10 & 73.00 \\
\hline BBB & 51.46 & 62.39 & 73.26 & & 85.00 & 96.70 & 106.48 & 115.49 & 124.60 \\
\hline BB & 159.45 & 168.40 & 200.88 & & 228.04 & 275.67 & 274.62 & 292.81 & 302.47 \\
\hline B & 331.31 & 330.78 & 372.86 & & 395.26 & 479.70 & 435.33 & 459.54 & 460.97 \\
\hline C & 482.45 & 629.55 & 658.31 & & 654.90 & 889.55 & 668.25 & 670.6 & 654.80 \\
\hline
\end{tabular}

Notes: This table reports descriptive statistics for the sample CDS spreads from May 2002 to May 2012. Panel A splits CDS contracts according to their times to maturity and reports sample means (in basis points), standard deviations, maximum and minimum values, and the number of observations. Panel B further splits each of the maturities according to the rating class and reports the average CDS spreads for a given rating-maturity sub-group.

by contributors. Stale prices may be reported, for example, if the CDS quotes are not updated by institutions. Markit ranks all contributors in terms of the number of days the submitted quote for the most liquid 5-year CDS contract remains unchanged. Then in the final calculations, the $50 \%$ of quotes with the smallest number of stale days are used, if the total number of contributors is below 13 , or $67 \%$ of quotes if there are 13 or more contributors. $^{11}$

Overall, our sample covers 431 firms (see Table 1). The firms are relatively evenly distributed across different industries, with the exception of financial firms, which are the smallest group with only seven firms in our sample. Vast majority of firms have CDSs with all maturities. Even the most rarely used 6-month CDS contract is issued for about $80 \%$ of the firms, with all but 2 firms having 5 -year CDSs. As far as the rating is concerned, the most frequent rating in our sample is $\mathrm{BBB}$, which represents about $39 \%$ of the firms. The least frequent rating is AAA, here we have only 3 firms, representing less than $1 \%$ of our sample.

The descriptive statistics of our entire sample are reported in Table 2. Panel A reports the descriptive statistics for different CDS maturities, and Panel B further splits the sample according to rating classes. Our CDS sample includes more than 3.6 million observations. The average CDS spread is $150.51 \mathrm{bps}$, with the maximum of 
Table 3. Recovery rates descriptive statistics.

\begin{tabular}{lcccccccc}
\hline & All & AAA & AA & A & BBB & BB & B \\
\hline Mean & 39.40 & 39.88 & 39.90 & 39.66 & 39.67 & 39.16 & 38.14 \\
Std & 2.67 & 0.42 & 0.84 & 1.16 & 1.42 & 2.94 & 5.57 & 6.42 \\
Max & 75.00 & 43.75 & 45.45 & 50.00 & 50.00 & 75.00 & 72.50 & 63.38 \\
Min & 7.50 & 36.92 & 20.00 & 26.08 & 20.83 & 15.00 & 7.50 & 7.50 \\
\# Obs & $3,658,096$ & 27,702 & 114,406 & 786,611 & $1,707,637$ & 545,326 & 389,567 & 86,847 \\
\hline
\end{tabular}

Notes: This table reports descriptive statistics (in percent) for the reported recovery rates from May 2002 to May 2012, for all CDS contracts as well as splitting the sample according to the rating class of the underlying security.

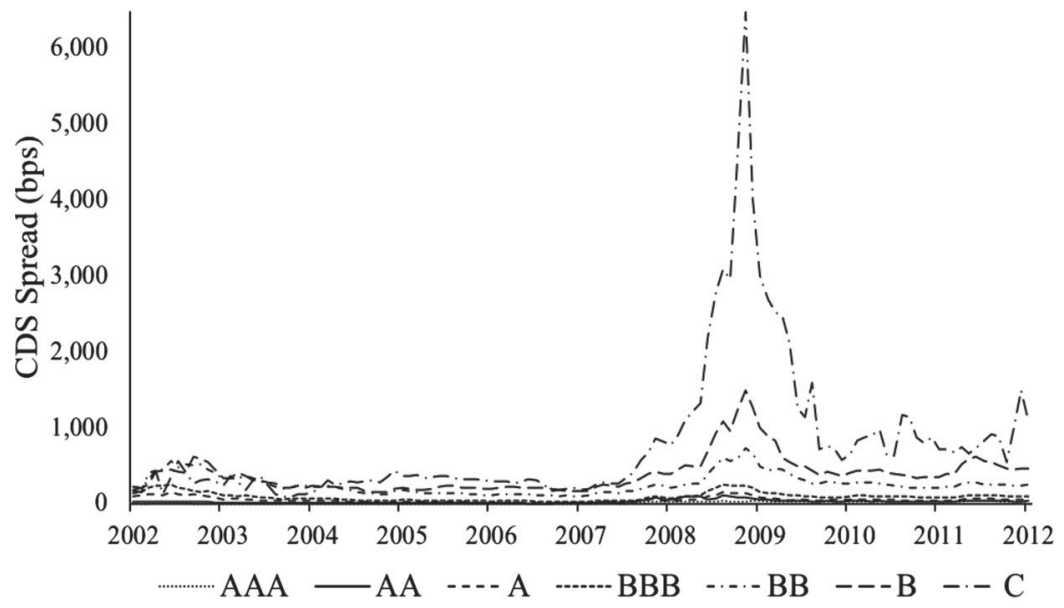

(i) CDS spreads

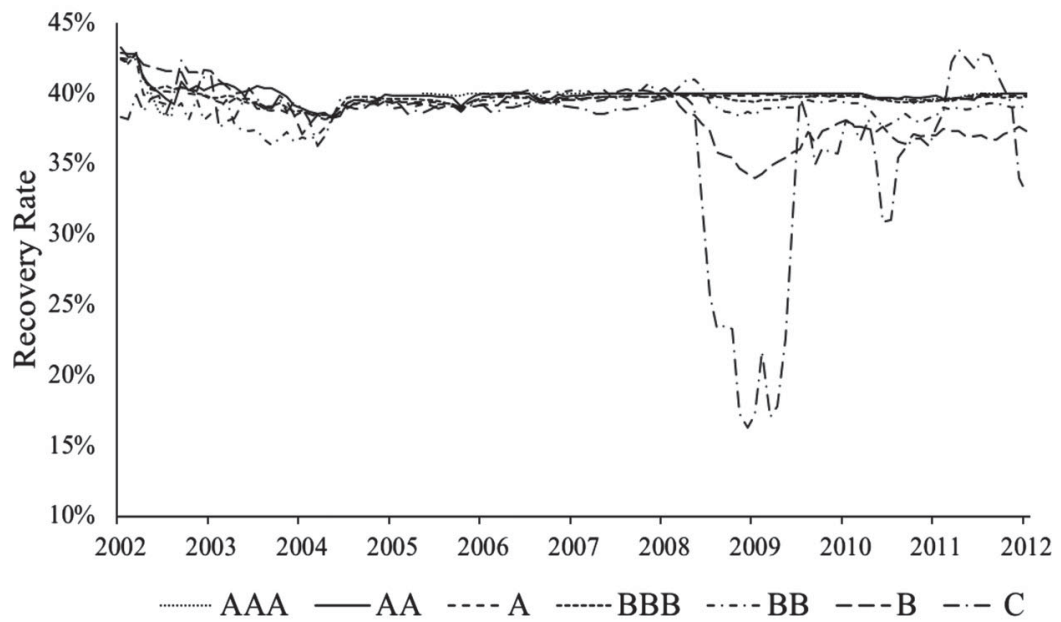

(ii) Recovery rates

Figure 1. Time series plot of CDS spreads and recovery rates. The top panel of the figure plots the time series of average CDS spreads for different rating classes. While taking the average, CDS with all maturities were considered. The bottom figure plots the time series of the recovery rates.

more than $20,000 \mathrm{bps}$ and the minimum of just $0.6 \mathrm{bps}$. The extraordinarily large maximum spread is due to the procedure used to annualize CDS spreads. Normally, the CDS spread should be within 10,000 bps; otherwise, the CDS buyers pay more than the nominal of the CDS contract. However, if firm's default is expected to happen within one year, the premium payment during a protection period is close to $10,000 \mathrm{bps}$, which results in 
the annualized CDS spread being above $10,000 \mathrm{bps} .{ }^{12}$ When we break down our sample into groups by time to maturity, the 5-year CDS has the largest number of observations (544 thousand observations) while 6-month CDS has the smallest number of observations (308 thousand observations). We also observe that the sample average CDS spread increases with the length of time to maturity; 6-month CDSs have the smallest sample average of $94 \mathrm{bps}$, while 10 -year CDSs have the largest average of $187 \mathrm{bps}$. There are substantial differences in the CDS spreads across rating classes, with CDS spreads monotonically increasing from AAA- to C-rated bonds for all maturities. For example, for the 6-month maturity the average CDS spread of $\mathrm{C}$ rated bond is more than 40 times larger than that of AAA rated bond ( 482.45 bps vs. $11.88 \mathrm{bps}$, respectively).

The reported average recovery rates are around $40 \%$ for all rating classes (see Table 3 ). There is, however, some variation in the recoveries. AAA-rated securities have the smallest variation in the reported recovery rates, with the standard deviation being only $0.42 \%$, whereas the volatility of the reported recovery rates for C-rated bonds is as high as $6.42 \%$. Since the recoveries are reported per security, CDS contracts with different maturities but with the same underlying bond have the same recovery rates.

Figure 1 plots the time series of the average CDS spreads and the average recovery rates for different rating classes. During the financial crisis 2007-2010, CDS spreads increase considerably, especially for speculative grade bonds, while recovery rates decrease, consistent with the findings on the negative correlation between default probability and recovery rates. ${ }^{13}$ Although changes in CDS spreads for speculative grade bonds are much larger in absolute values, reaching over 60\% on March 2009 for C-rated bonds, investment grade securities exhibit the same time series pattern of their CDS spreads. ${ }^{14}$ For example, for AA-rated bonds, the CDS spreads have increased by a factor of 12 from 8.9 bps in March 2007 to 110 bps in December 2008. Interestingly, this pattern is not so evident for recovery rates. During the finial crisis the reported recovery rates went substantially down for BB-, B-, and C-rated bonds, but remained relatively stable for higher rated bonds. It suggests that the extremely high CDS spreads for speculative grade bonds during the financial crisis were driven by both increasing default probability and decreasing recovery rates, whereas investment grade bonds were subject only to increasing default risk.

To facilitate the empirical analysis, we assign a numerical value to each rating class. We start with assigning 1 to AAA, and then move in steps of one down the ratings, such as, for example, BBB is assigned the numerical value of 4 , and $C$ is assigned 7.

\section{Fitted CDS curves}

The Nelson-Siegel model is fitted using all CDS spreads of the same rating class for a particular day. This process is repeated for each rating class and for each day in our sample period. As an illustration, we first show the fitting results for 23 December 2008, and then discuss the overall properties of the fitted curves and corresponding residuals.

\subsection{Fitted CDS curves: Example}

Figure 2 shows the estimation results for 23 December 2008. The fitted CDS curves do not cross, and the fitted values are consistent with the order of the ratings. The CDS-implied hazard rates for firms with the best rating (AAA) are the lowest, and the implied hazard rates for the firms with the worst rating $(\mathrm{C})$ are the highest. Furthermore, the CDS curves of the investment grades are flatter than those for the junk grades, suggesting a stable and constant outlook for the investment grade firms. In contrast, with the convex curve for the junk grade firms, the CDS market appears to be more concerned about the short-term solvency of firms with low credit quality.

To alleviate a potential concern that the fitted curves are affected by outliers, Figure 3 plots the fitted curves together with the actual CDS spreads for each rating class on 23 December 2008. In general, the Nelson-Siegel model captures well the variations in CDS spreads. For some ratings, for example AAA, where there are only few observations, the fitted curve just smooths over the observations. Where there are more observations, for example BBB, the curve reflects the main trend. ${ }^{15}$ 


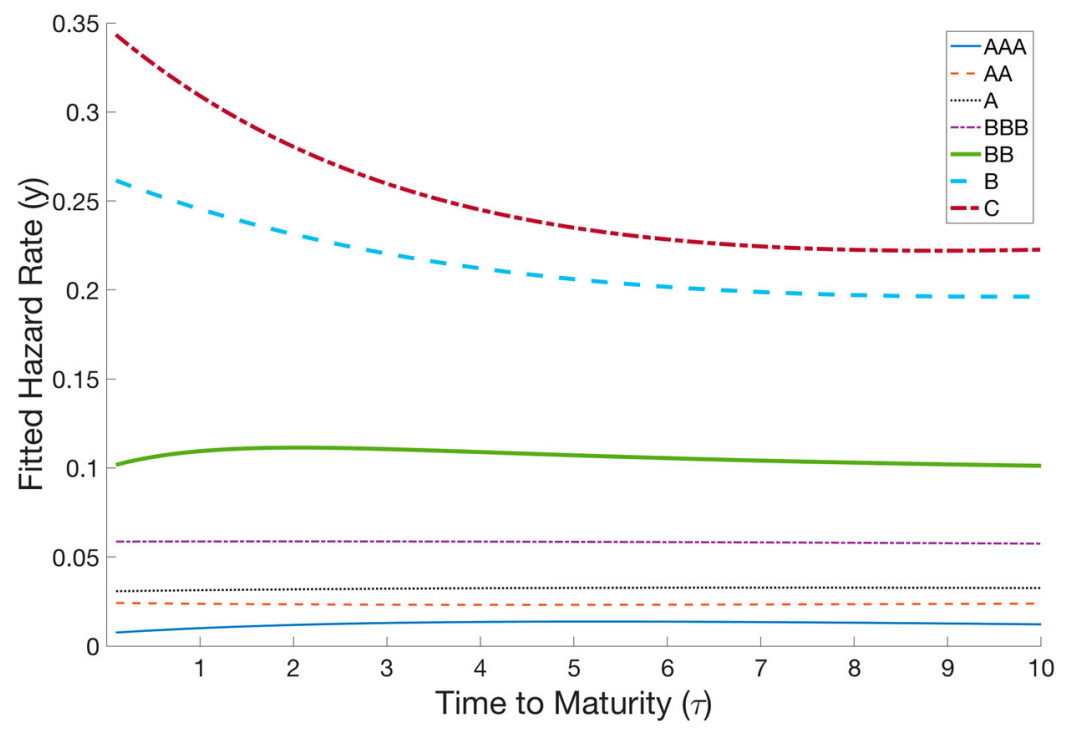

Model Parameters for Each Rating Class

\begin{tabular}{rrrrrrrr}
\hline & AAA & AA & A & BBB & BB & B & C \\
\hline$\beta_{0}$ & 0.000 & 0.030 & 0.014 & 0.042 & 0.094 & 0.285 & 0.308 \\
$\beta_{1}$ & 0.007 & -0.006 & 0.017 & 0.017 & 0.006 & -0.022 & 0.040 \\
$\beta_{2}$ & 0.034 & -0.012 & 0.031 & 0.019 & 0.048 & -0.263 & -0.348 \\
$m$ & 3.913 & 5.176 & 9.849 & 9.871 & 1.363 & 5.950 & 4.319 \\
\hline
\end{tabular}

Figure 2. Rating-based CDS curves and parameter values for 23 December 2008. This figure plots the rating-based CDS curves fitted using the Nelson-Siegel model below:

Table 4. Average values of fitted Nelson-Siegel parameters.

\begin{tabular}{|c|c|c|c|c|c|c|c|}
\hline & AAA & $\mathrm{AA}$ & $A$ & BBB & $\mathrm{BB}$ & B & $C$ \\
\hline$\beta_{0}$ & 0.007 & 0.010 & 0.009 & 0.012 & 0.018 & 0.056 & 0.141 \\
\hline$\beta_{1}$ & -0.006 & -0.004 & -0.003 & -0.001 & 0.010 & 0.007 & -0.029 \\
\hline$\beta_{2}$ & 0.002 & 0.006 & 0.017 & 0.040 & 0.093 & 0.072 & -0.013 \\
\hline$m$ & 5.518 & 5.255 & 5.749 & 6.852 & 5.838 & 4.056 & 3.390 \\
\hline
\end{tabular}

Note: This table reports the average values of the parameters of the Nelson-Siegel model for different rating classes fitted from May 2002 to May 2012.

\subsection{Properties of the fitted CDS curves and the residuals}

Table 4 reports the average values of the parameters of the Nelson-Siegel model over our complete sample for seven rating classes. $\beta_{0}$ monotonically increases from 0.007 for AAA to 0.141 for $\mathrm{C}$ rating classes, indicating the increase in the long-term hazard rate for bonds with worse rating classification.

The resulting average rating curves are presented in Figure 4. We can see that all the rating curves are in the correct order and do not cross. Since we do not impose any restrictions on crossings of the rating curves, we further check if and how often crossings happen in our sample period. A crossing would indicate that the ratingimplied hazard rate of better ratings is higher than that of worse ratings. To this extend, we compute a percentage of days per year during which any of the rating curves is misplaced relative to other curves. We find that this happens, on average, in $6.68 \%$ of days per year. This number is largely driven by the years 2003 and 2008 . In 2003 , the crossings happened in $28 \%$ of days predominantly between BB, B, and C rating curves. This is likely to be due to low liquidity of these CDS contracts during the early periods. During the financial crisis of 2008, 


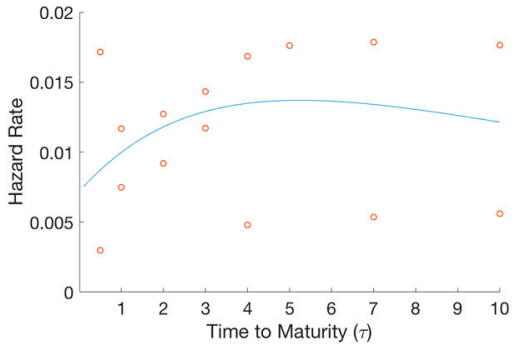

(i) AAA

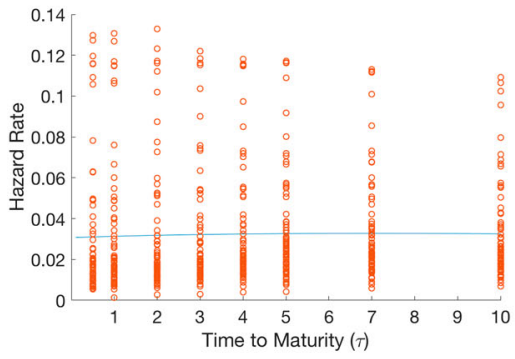

(iii) $\mathrm{A}$

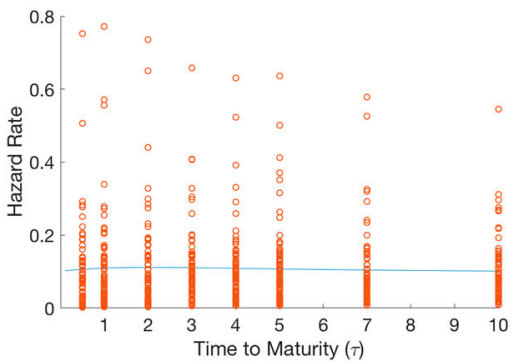

(v) $\mathrm{BB}$

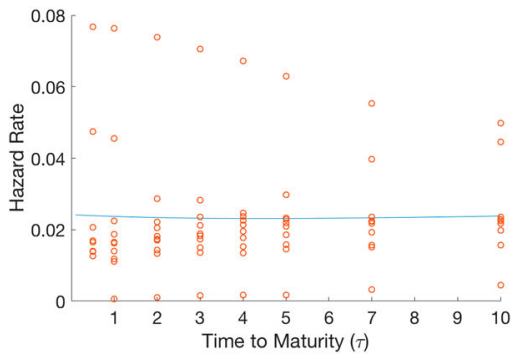

(ii) $\mathrm{AA}$

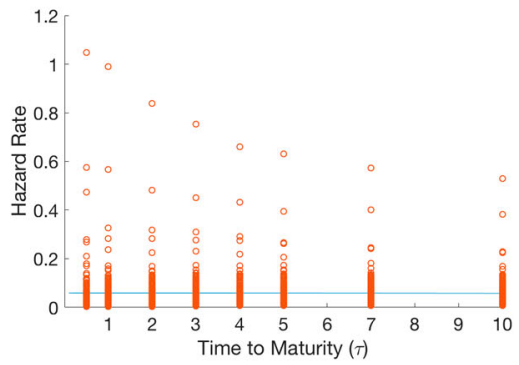

(iv) $\mathrm{BBB}$

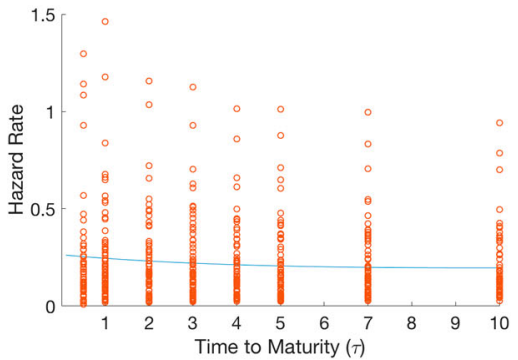

(vi) $\mathrm{B}$

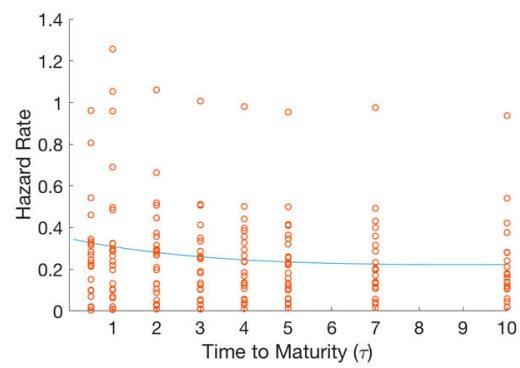

(vii) $\mathrm{C}$

Figure 3. Rating-based CDS curves for 23 December 2008. This figure plots the rating-based CDS curves, $y(\tau)$, fitted using the Nelson-Siegel model for each rating class. The symbol 'o' denotes the actual CDS-implied hazard rate $(h)$. 


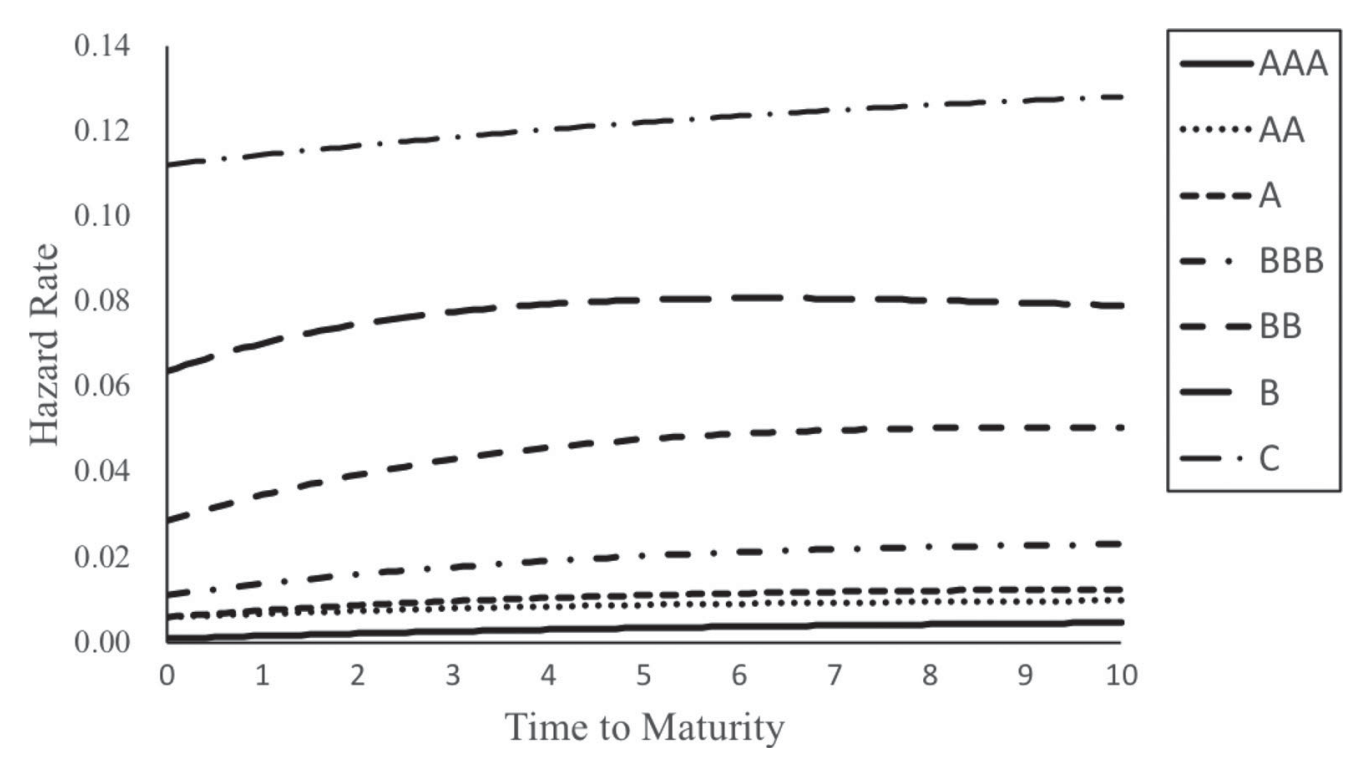

Figure 4. Average rating-implied hazard rate curves. This figure plots the average rating-implied hazard rate curves for different rating classes based on the calibration of the Nelson-Siegel model for the sample period from May 2002 to May 2012.

we observe crossings in 35\% of days. These crossings are associated with AA and A rating curves. Before the financial crisis, AA rated firms were considered as very low default risk; but during the financial crisis, AA-rated securities were perceived as riskier. Excluding these two years, the average share of days with curves' crossings is just about $1 \%$ per year. Thus, we are confident that the Nelson-Siegel model provides a reasonable fit for the rating-implied hazard rates.

Table 5 reports the descriptive statistics of the fitted values $y$ from the Nelson-Siegel model, and Table 6 reports those of the residual components $e$. The average fitted value, $y$, monotonically increases from $207 \mathrm{bps}$ for the 6-month CDSs to 341 bps for the 10 -year CDSs. ${ }^{16}$ Also, within each tenor, the average fitted values monotonically increase from AAA rating to $\mathrm{C}$ rating, indicating that the model captures well the pattern in hazard rates. The average residuals, $e$, vary from 1.21 bps for 5-year AAA CDSs to -484 bps for 6-month CDSs written on C-rated securities. Overall, the average values of the residuals are largely negative, but exhibit substantial variation. ${ }^{17}$

We now analyze the properties of the residual term $(e)$ in more detail and its relation to individual firm characteristics. We choose 5-year CDS contracts as representative and compute relative deviations from the

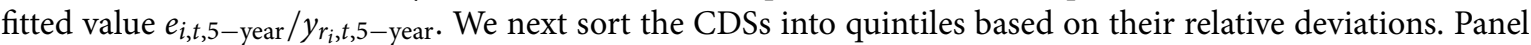
A of Table 7 reports the average firm characteristics sorted based on the relative deviation. The group with the largest positive deviations contains slightly larger (average size over 29 billion) with the lowest leverage ratios (the average debt-to-assets ratio of 0.64 ). The average deviation for the highest quintile group is 1.16 (with the average CDS spread being $439 \mathrm{bps}$ ) and that for the lowest quintile group is -0.64 (with the average CDS spread being $75 \mathrm{bps}$ ). There is no systematic difference in liquidity of the CDS contracts across the quintiles. The average number of contributors per CDS contact is very similar across the sub-groups and lies between 5.52 and 5.77 contributors per CDS. We do not find any obvious trend for the firms' rating. The average rating for the lowest quintile group is 4.46 (approximately BBB rating) and that for the highest quintile group is 4.24 (approximately $\mathrm{BBB}$ rating, too). This is to be expected: as we form our curves based on ratings, a firm's rating should not be a categorizing factor for the deviations.

The analysis above does not suggest, however, that larger firms have higher CDS spreads and higher deviations. When sorting the firms by size (Panel B of Table 7), the size variation across the portfolios is substantially larger than the size variation across the portfolios sorted on the relative deviation. The average firm size in the first quintile is 2 billion dollars and in the fifth quintile 226 billion dollars. We found that CDS spreads decrease 
Table 5. Descriptive statistics of Nelson-Siegel rating-based fitted values of hazard rates $(y)$.

\begin{tabular}{|c|c|c|c|c|c|c|c|c|}
\hline & 6-month & 1-year & 2-year & 3-year & 4-year & 5-year & 7-year & 10-year \\
\hline \multicolumn{9}{|c|}{ Panel A: Fitted value by tenor } \\
\hline Mean & 207.10 & 224.74 & 251.24 & 278.81 & 320.30 & 319.49 & 328.90 & 341.42 \\
\hline Std & 398.22 & 369.97 & 350.80 & 346.31 & 368.16 & 341.21 & 331.54 & 325.59 \\
\hline Max & 7439.95 & 7407.89 & 7345.04 & 7283.92 & 7224.56 & 7166.99 & 7057.25 & 6905.98 \\
\hline Min & -2.49 & 2.25 & 2.69 & 3.70 & 4.98 & 5.08 & 8.31 & 11.13 \\
\hline \#Obs & 308,245 & 468,378 & 471,722 & 506,898 & 359,003 & 544,392 & 504,271 & 495,187 \\
\hline \multicolumn{9}{|c|}{ Panel B: Fitted value by tenor and rating } \\
\hline AAA & 20.86 & 20.86 & 27.49 & 33.62 & 40.79 & 42.52 & 51.75 & 60.51 \\
\hline AA & 56.89 & 51.19 & 59.63 & 65.99 & 88.14 & 78.89 & 89.70 & 99.03 \\
\hline A & 64.31 & 71.15 & 83.94 & 94.96 & 115.85 & 112.99 & 124.83 & 135.98 \\
\hline BBB & 113.44 & 132.45 & 154.41 & 173.05 & 198.41 & 201.15 & 219.32 & 234.20 \\
\hline BB & 291.68 & 307.73 & 361.07 & 399.01 & 477.31 & 459.08 & 486.01 & 500.57 \\
\hline B & 765.89 & 718.59 & 764.18 & 808.07 & 923.06 & 852.81 & 884.43 & 889.61 \\
\hline C & 1216.57 & 1183.34 & 1181.09 & 1167.16 & 1264.78 & 1137.98 & 1161.84 & 1163.06 \\
\hline
\end{tabular}

Notes: This table reports descriptive statistics of the fitted values of the hazard rates using the Nelson-Siegel model (y) to the sample of CDS spreads from May 2002 to May 2012. Panel A splits the fitted hazard rates according to the time to maturity, and it reports sample means (in basis points), standard deviations, maximum and minimum values. Panel B further splits each of the maturities according to the rating class and reports the average hazard rates for a given rating-maturity sub-group.

Table 6. Descriptive statistics of Nelson-Siegel residuals (e).

\begin{tabular}{|c|c|c|c|c|c|c|c|c|}
\hline & 6-month & 1-year & 2-year & 3-year & 4-year & 5-year & 7-year & 10-year \\
\hline \multicolumn{9}{|c|}{ Panel A: NS residual by tenor } \\
\hline Mean & -60.05 & -52.06 & -51.16 & -49.98 & -49.15 & -39.29 & -39.75 & -39.44 \\
\hline Std & 363.44 & 397.59 & 362.29 & 337.77 & 349.60 & 326.91 & 304.59 & 291.36 \\
\hline Max & $10,711.70$ & $22,213.45$ & $10,495.51$ & 9281.39 & 9331.23 & 9046.60 & 8992.77 & 8695.71 \\
\hline Min & -4688.37 & -3983.70 & -3429.36 & -3122.73 & -3001.48 & -3569.45 & -3221.28 & -4276.76 \\
\hline \#Obs & 308,245 & 468,378 & 471,722 & 506,898 & 359,003 & 544,392 & 504,271 & 495,187 \\
\hline \multicolumn{9}{|c|}{ Panel B: NS residual by tenor and rating } \\
\hline AAA & -1.10 & -0.94 & -0.52 & -0.79 & -0.74 & 1.21 & 0.71 & 0.15 \\
\hline$A A$ & -19.59 & -16.54 & -18.56 & -20.33 & -27.11 & -20.33 & -22.08 & -23.08 \\
\hline A & -23.71 & -19.18 & -22.63 & -20.78 & -30.97 & -16.39 & -17.13 & -15.21 \\
\hline BBB & -28.37 & -29.58 & -33.59 & -32.59 & -38.21 & -25.09 & -28.36 & -28.07 \\
\hline $\mathrm{BB}$ & -33.57 & -35.03 & -35.32 & -27.81 & -26.86 & -9.12 & -9.01 & -7.12 \\
\hline B & -276.79 & -220.87 & -196.12 & -196.99 & -185.51 & -170.31 & -163.56 & -163.87 \\
\hline C & -484.42 & -255.54 & -204.10 & -182.72 & 57.99 & -110.55 & -129.04 & -146.32 \\
\hline
\end{tabular}

Notes: This table reports descriptive statistics of the residuals $e$ (in basis points), measured as deviations of individual CDS-implied hazard rates from their fitted values based on Nelson-Siegel model from May 2002 to May 2012. Panel A splits the residuals according to the time to maturity, and it reports sample means (in basis points), standard deviations, maximum and minimum values. Panel B further splits each of the maturities according to the rating class and reports the average hazard rates for a given rating-maturity sub-group.

from 297 bps for small firms to 126 bps for large firms. Larger firms also tend to have better rating compared to small firms (3.39 vs. 5.05) and more liquid CDS contracts. The average number of contributors increases from 3.83 for small firms to 6.43 for large firms. This indicates that in each relative deviation quintile there is a mixture of large and small firms and that firm size is not the key determinant of the relative deviation. Consequently, we do not observe much variation in relative deviations when sorting on firm size.

\section{CDS convergence to the fitted curves}

To further assess the importance of the fitted CDS curves, we test if the residual components are persistent or transient. If the former is true, one needs to search for other factors that drive long-term average CDS spreads; if the latter is proved to be the case, rating-based information could be sufficient to assess long-term average CDS spread.

As a preliminary step, we test each individual time series of firm-tenor specific CDS-implied hazard rates $(h)$ and rating-implied hazard rates $(y)$ for stationarity. In particular, for each individual time series, we run the 
Table 7. Properties of the residual term.

\begin{tabular}{|c|c|c|c|c|c|}
\hline \multicolumn{6}{|c|}{ Panel A: Sort on relative deviation } \\
\hline & Negative $=[1]$ & {$[2]$} & [3] & [4] & Positive $=[5]$ \\
\hline$e / y$ & -0.64 & -0.42 & -0.22 & 0.08 & 1.16 \\
\hline Size (\$ Million) & $29,104.76$ & $45,104.07$ & $48,436.61$ & $65,587.98$ & $77,567.74$ \\
\hline Debt (\$ Million) & $21,507.23$ & $35,357.75$ & $38,304.26$ & $55,428.44$ & $69,144.39$ \\
\hline Lev $=($ Debt/assets $)$ & 0.64 & 0.64 & 0.66 & 0.69 & 0.72 \\
\hline Rating & 4.46 & 4.04 & 4.02 & 4.18 & 4.24 \\
\hline \# Contributor & 5.52 & 5.69 & 5.77 & 5.65 & 5.54 \\
\hline CDS Spread (bp) & 74.67 & 100.57 & 137.69 & 215.98 & 438.95 \\
\hline \multicolumn{6}{|c|}{ Panel B: Sort on firm size } \\
\hline & Small size $=[1]$ & {$[2]$} & {$[3]$} & {$[4]$} & Large size $=[5]$ \\
\hline$e / y$ & 0.00 & -0.04 & -0.04 & -0.03 & 0.07 \\
\hline Size (\$ Million) & 2071.66 & 4942.45 & 9843.25 & $21,802.22$ & $225,922.31$ \\
\hline Debt (\$ Million) & 1393.45 & 3163.38 & 6156.92 & $14,321.33$ & $193,697.99$ \\
\hline Lev $=$ (Debt/assets) & 0.69 & 0.63 & 0.62 & 0.65 & 0.74 \\
\hline Rating & 5.05 & 4.56 & 4.15 & 3.81 & 3.39 \\
\hline \# Contributor & 3.83 & 5.09 & 6.02 & 6.79 & 6.43 \\
\hline CDS Spread (bp) & 297.29 & 230.85 & 164.80 & 152.59 & 125.88 \\
\hline
\end{tabular}

Notes: This table sorts all CDS observations into quintile portfolios based on the size of the relative deviation of the CDS-implied hazard rate from the rating-implied one $(e / y)$ (Panel A) and based on firm size (Panel B). For each quintile portfolio, it reports the average relative deviation, firm size, debt value, leverage ratio, rating, as well as the number of CDS contributors and the corresponding CDS spreads. The sample period is from May 2002 to May 2012.

Table 8. Augmented Dicky-Fuller test for stationarity of the hazard rates.

\begin{tabular}{|c|c|c|c|c|c|c|c|c|c|}
\hline \multirow[b]{2}{*}{ Sign. level } & \multicolumn{3}{|c|}{ Hazard rate $(h)$} & \multicolumn{3}{|c|}{ Nelson-Siegel fitted value $(y)$} & \multicolumn{3}{|c|}{ Residual from regressing $h$ on $y$} \\
\hline & $1 \%$ & $5 \%$ & $10 \%$ & $1 \%$ & $5 \%$ & $10 \%$ & $1 \%$ & $5 \%$ & $10 \%$ \\
\hline ALL & 91.69 & 83.83 & 76.10 & 96.31 & 92.31 & 87.90 & 43.60 & 25.16 & 17.97 \\
\hline AAA & 100.00 & 100.00 & 87.50 & 100.00 & 100.00 & 100.00 & 8.33 & 0.00 & 0.00 \\
\hline AA & 98.68 & 92.11 & 81.58 & 94.74 & 82.89 & 72.37 & 13.16 & 9.21 & 5.26 \\
\hline$A$ & 90.16 & 83.24 & 73.41 & 94.90 & 91.80 & 86.52 & 27.87 & 12.57 & 8.38 \\
\hline BBB & 88.88 & 78.82 & 70.65 & 94.60 & 89.45 & 84.87 & 44.08 & 25.06 & 18.61 \\
\hline BB & 93.43 & 86.13 & 80.66 & 98.36 & 95.62 & 92.34 & 54.63 & 33.94 & 24.14 \\
\hline B & 97.26 & 93.52 & 88.53 & 99.75 & 98.25 & 95.26 & 56.27 & 38.08 & 27.03 \\
\hline C & 94.57 & 86.05 & 75.97 & 99.22 & 93.02 & 87.60 & 43.41 & 15.50 & 8.53 \\
\hline
\end{tabular}

Notes: This table reports the percentage (\%) of individual time series of CDS-implied hazard rates ( $h$ ), Nelson-Siegel rating-based fitted values $(y)$, and residuals from the individual time series regressions of $h$ on $y$, for which the augmented Dicky-Fuller test with a time trend and 20 lags fails to reject the null hypothesis of no unit root. The results are reported for all CDSs in our sample from May 2002 to May 2012, as well as for individual rating classes, using different critical values (corresponding to $1 \%, 5 \%$, and $10 \%$ significance levels).

augmented Dicky-Fuller test, allowing for a time trend and using 20 lags. The results in Table 8 illustrate that for the vast majority of the individual time series we cannot reject the null of a unit root at any convectional level. We further run individual time series regressions of the CDS-implied hazard rates on the rating-implied hazard rates and repeat the unit root test based on the residuals from this regression. In majority of cases, the unit root of the residuals can be rejected (at least at the 10\% significance level), suggesting that individual CDS-implied hazard rates rating-implied hazard rates are cointegrated.

Having established that most of individual time series of the CDS-implied hazard rates and Nelson-Siegel fitted values are cointegrated, we now test if positive (negative) deviation induces a decrease (increase) in $h$ over time. To answer this question, we estimate a panel regression in the spirit of the error correction model. Here we regress changes in the individual CDS-implied hazard rates $(h)$ onto changes in rating-implied hazard rates $(y)$, and the past deviations (e). The model allows us to test if, on average, the deviations are corrected over time and the individual CDS-implied hazard rates converge towards the rating-based hazard rates. Specifically, we run the following panel regression with firm-maturity fixed effects and report cluster-robust standard errors (clustered 
Table 9. Panel regression results for convergence of CDS-implied hazard rates to their rating curves.

\begin{tabular}{|c|c|c|}
\hline & Model 1 & Model 2 \\
\hline$\Delta y_{r_{i}, t, \tau}$ & $\begin{array}{c}0.285^{* * *} \\
{[6.93]}\end{array}$ & $\begin{array}{c}0.545^{* * *} \\
{[7.25]}\end{array}$ \\
\hline$e_{i, t-5, \tau}$ & $\begin{array}{c}-0.035^{* * *} \\
{[-8.34]}\end{array}$ & \\
\hline$e_{i, t-20, \tau}$ & & $\begin{array}{c}-0.127^{* * *} \\
{[-8.41]}\end{array}$ \\
\hline Firm-maturity dummies & Yes & Yes \\
\hline Adj $R$-sqr & 0.05 & 0.15 \\
\hline \# Obs & $3,482,714$ & $3,342,077$ \\
\hline \multicolumn{3}{|c|}{$\begin{array}{l}\text { Notes: This table reports the panel regression results of the changes in indi- } \\
\text { vidual CDS-implied hazard rates onto changes in the rating-implied hazard } \\
\text { rates, as well as past deviation. The sample period is from May } 2002 \text { to May } \\
2012 \text {. Model } 1 \text { uses time difference of one week ( } 5 \text { trading days), and Model } \\
2 \text { uses time difference of one month ( } 20 \text { trading days). The robust stan- } \\
\text { dard errors clustered by firm are used, and the corresponding } t \text {-statistic is } \\
\text { reported in square brackets. } * * *, * * \text {, and * denote, respectively, statistical } \\
\text { significance at the } 1 \%, 5 \% \text {, and } 10 \% \text { levels. }\end{array}$} \\
\hline
\end{tabular}

by firms) for the estimated coefficients:

$$
\Delta h_{i, t, \tau}=\beta_{0}+\beta_{1} \Delta y_{r_{i}, t, \tau}+\beta_{2} e_{i, t-j, \tau}+\eta_{i, t, \tau},
$$

where $\Delta$ indicates a change in the variable between time $t$ and time $t-j$. We consider the weekly and monthly difference in our panel regression (i.e. $j=5$ and $j=20$ trading days). $y_{r_{i}, t, \tau}$ is the hazard rate obtained from the relevant CDS curve for firm $i$ and CDS maturity $\tau$ at the corresponding rating $r . \Delta y$ could be due to changes in the various market factors and conditions, such as liquidity, risk premia, perception of the aggregate credit risk in the economy, or supply and demand shocks in the CDS market. $e$ measures the past deviation of the CDSimplied hazard rate, $h$, from the fitted rating curve, $y$. A negative $\beta_{2}$ indicates convergence of $h$ towards $y$, further supporting the importance of the rating curves as a source of credit-risk-related information for investors.

Table 9 reports the panel regression results. Model 1 reports the results for one week changes and Model 2 reports the results for one month changes. The loadings on $\Delta y_{r_{i}, t, \tau}$ and $e_{i, t-j, \tau}$ are all significant at the $1 \%$ level. Positive loadings on $\Delta y_{r_{i}, t, \tau}$ indicate that times-series movement of the fitted rating curves explains the movement of the individual-CDS implied hazard rates. Regarding the past residual term, we observe negative loadings on $e_{i, t-j, \tau}$ for both 5- and 20-day differences. CDS-implied hazard rate increases to correct for a negative residual in the previous period, and decrease for a positive residual, thus, converging to the corresponding ratingbased curve over time.

To assess the robustness of our results, we repeat the analysis separately for each individual year from 2002 to 2012, different rating classes, individual CDS maturities, and industries. The results are tabulated in Appendix 1. The robustness check confirms that our results are not driven by any particular sub-set of data. In particular, over 7 rating classes, the convergence results are not significant only for AA class. ${ }^{18}$ The results for all other rating classes are consistent with the main findings. The estimated coefficients are also quite similar across rating classes, with those for monthly changes being somewhat larger in absolute values for CDSs written on lowrated bonds ( $\mathrm{B}$ and $\mathrm{C}$ rating classes), indicating faster convergence to the rating curves for riskier underlyings. Over the period 2002 to 2012, the convergence in hazard rates is statistically significant in all years. The fastest convergence can be seen in year 2002, whereas the slowest convergence is detected during the year 2007, thus, at the start of the financial crisis. Splitting the sample by the CDS maturity also produces statistically significant convergence rate for all maturities. As far as different industries are concerned, the loadings on the past residual term are always negative; however, they lack strong statistical support for Consumer Goods, Financials, and Telecommunication Services. Overall, we find positive loadings on $\Delta y_{r_{i}, t, \tau}$ (not reported to save space) and negative loadings on $e_{i, t-j, \tau}$ throughout all specification. The results reinforce our previous finding that the individual CDS-implied hazard rates tend to converge to the respective fitted rating curves over time. 


\subsection{Convergence speed}

The panel regression results in the previous section suggest that individual CDS spreads tend to converge to the respective fitted CDS curves over time. In this section, we further investigate the speed of this convergence on the aggregate level and based on individual CDS deviation.

The key characteristic of the convergence speed at the aggregate level is the estimated parameter $\beta_{2}$. To assess the average speed of convergence, we conduct the impulse-response analysis, using the estimated coefficients of Equation (7). In our panel regression framework, the expected change in the CDS-implied hazard rate can be expressed as:

$$
E\left[\Delta h_{t}\right]=\beta_{0}+\beta_{1} \Delta y_{t}+\beta_{2} e_{t-1} .
$$

Equation (8) implies that, if there is a unit increase in residual term $e_{0}=1$ at $t=0$, then the resulting timeseries of CDS-implied hazard rates can be expressed as $h_{t}=\left(1+\beta_{2}\right)^{t}$, assuming that $y_{0}=0$ and $\beta_{0}=0$. If $\beta_{2}<0$, then $h_{t}$ converges to 0 . The impulse-response analysis is detailed in Appendix 2 .

Figure 5 plots the impulse-response functions based on our estimates of $\beta_{2}$ for 5 - or 20 -day periods. For the 5 -day case, after one year (52 weeks) $15 \%$ of a unit shock in the residual $e$ is still reflected in the individual CDSimplied hazard rates. During slow convergence periods, such as year 2007 , about $17 \%$ of the unit shock is still visible in the CDS-implied hazard rates after one year. At the same time, during periods of fast convergence (e.g. year 2002) the unit shock decreases to $15 \%$ of its level already after 9 weeks, and it becomes negligibly small in less than 20 weeks.

Since the estimate of $\beta_{2}$ is obtained from a panel regression, it can be interpreted as the average convergence speed. Since there may be substantial variations in individual CDSs over time, we now analyze the individual realized convergence speed in our sample. We define the individual realized convergence speed, $s$, as

$$
s_{i, t, \tau}=\log \frac{\left|h_{i, t, \tau}-y_{r_{i}, t, \tau}\right|}{\left|h_{i, t-j, \tau}-y_{r_{i}, t-j, \tau}\right|}, \quad j=5 \text { or } 20 \text { days, }
$$

where $h_{i, t, \tau}$ is the time $t, \tau$-maturity CDS-implied hazard rate from Equation (4) for firm $i$, and $y_{r_{i}, t, \tau}$ is the time $t$, $\tau$-maturity hazard rate for the rating $r$ to which firm $i$ belongs. Therefore, if the distance between $h_{i, t, \tau}$ and $y_{r_{i}, t, \tau}$ (i.e. $\left.\left|h_{i, t, \tau}-y_{r_{i}, t, \tau}\right|\right)$ is smaller than the distance between $h_{i, t-j, \tau}$ and $y_{r_{i}, t-j, \tau}$ (i.e. $\left|h_{i, t-j, \tau}-y_{r_{i}, t-j, \tau}\right|$ ), it means that $h$ is approaching $y$ from time $t-j$ to $t$. If $\left|h_{i, t, \tau}-y_{r_{i}, t, \tau}\right|$ is larger than $\left|h_{i, t-j, \tau}-y_{r_{i}, t-j, \tau}\right|$, it means that $h$ is moving away from $y$. The smaller the ratio of the two, the faster is the convergence speed.

After taking natural logarithm of the ratio, the convergence speed is interpreted as follows:

$$
s_{i, t, \tau} \begin{cases}<0, & h \text { is approaching } y \text { (convergence); } \\ \geq 0, & h \text { is moving away from } y \text { (divergence). }\end{cases}
$$

Larger positive values of $s_{i, t, \tau}$ indicate $h$ is moving faster away from $y$, while the larger negative values of $s_{i, t, \tau}$ indicate $h$ is approaching faster towards $y$.

Figure 6 plots the monthly convergence speed for $j=5$ and 20 days. Here we use all daily observations in a month to calculate monthly convergence speed $s_{m}$ as the average of daily $s_{i, t, \tau}$ within this month. Not surprisingly, we find a mixed level of convergence speed over the sample period and $s_{m}$ is particularly volatile during the 2008 financial crisis.

The descriptive statistics for convergence speed $s_{m}$ are reported in Table 10 (5-day intervals) and Table 11 (20day intervals). The average $s_{m}$ for the 5-day and 20-day cases are both negative. There are, however, considerable variations across maturities and ratings. For example, on average the strongest convergence is observed for 20day steps for 6-month CDS contracts written on AA underlying. The convergence of -0.022 is 10 times stronger than that of the average contract. Some tenors, e.g. 4-year CDS contracts, even exhibit divergence on average (the average $s_{m}=0.01$ ). At the same time, even for these tenors the convergence speed is highly volatile $(0.136)$ and for individual contacts can vary from 0.439 to -0.382 .

Given that there is no clear pattern in individual convergence speed across ratings and maturities, we test if the convergence speed depends on the magnitude of the deviation $\left(\left|e_{i, t-j, \tau}\right|\right):$ if $h_{i, t-j, \tau}$ is close to $y_{r_{i}, t-j, \tau}$, the 


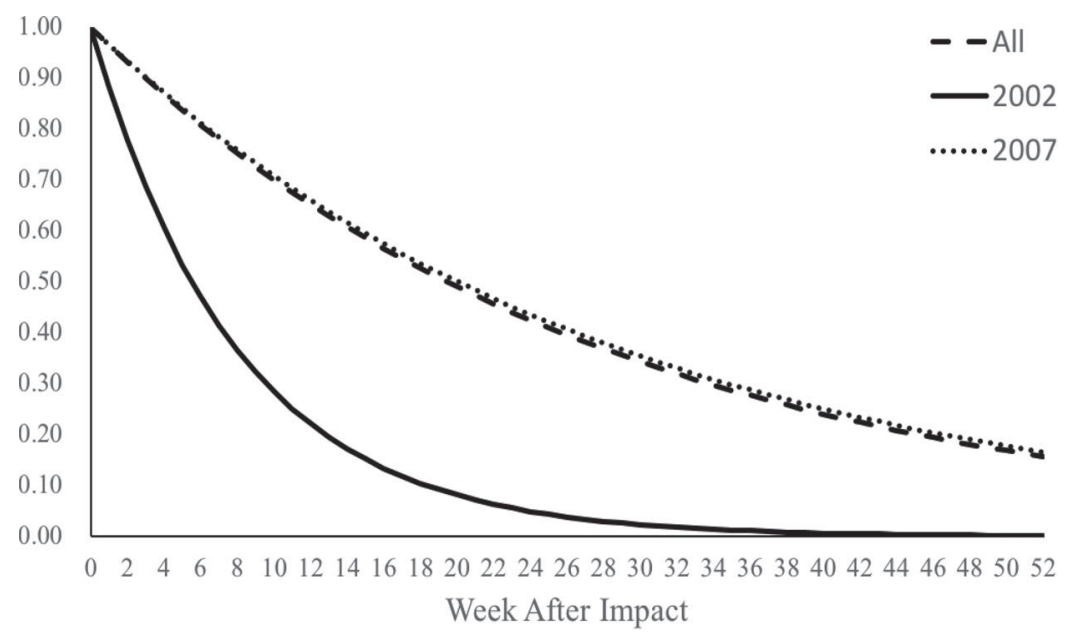

(i) 5-day intervals

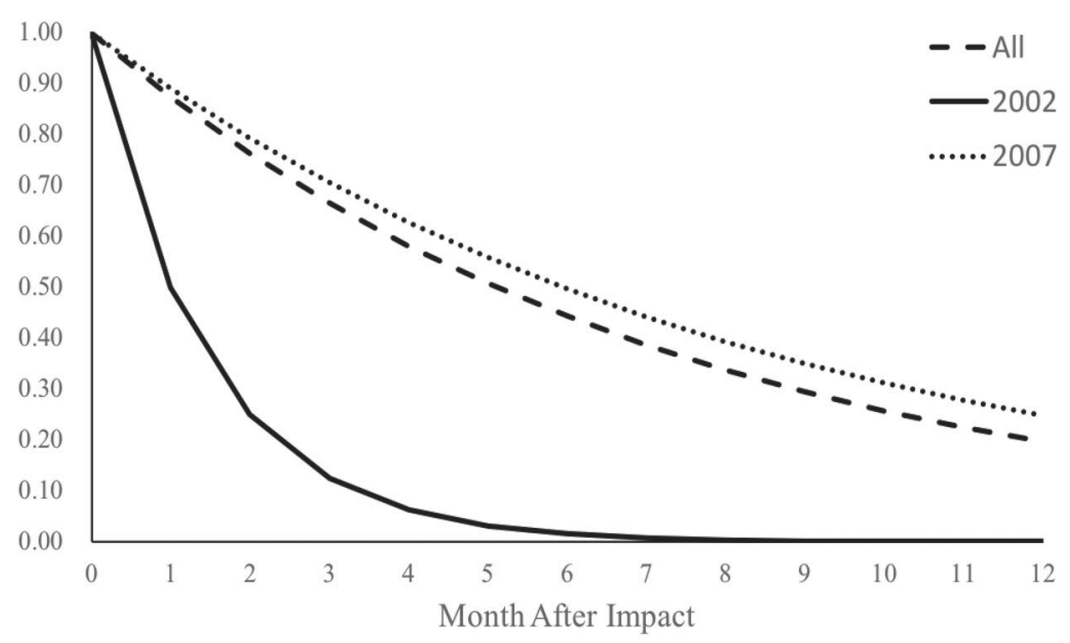

(ii) 20-day intervals

Figure 5. Impulse-response function. This figure plots the impulse-response function of the changes in the individual CDS-implied hazard rates to a unit shock to the deviation from the rating-implied hazard rate curves. The upper plot uses one-week intervals, and the bottom plot uses monthly intervals. Each plot depicts the functions related to the average estimated convergence speed, as well as the ones estimated for the year 2002 (the fastest convergence) and 2007 (the slowest convergence).

propensity to converge may be smaller, whereas the propensity to converge may be higher for larger deviations. We use the relative deviation measure $\left(e_{i, t-j, \tau} / y_{r_{i}, t-j, \tau}\right)$ to remove the scale of $y$ and to prevent undue influence of outliers. To test our hypothesis, we sort our daily $s_{i, t, \tau}$ into five portfolios, based on their past relative deviations, $e_{i, t-j, \tau} / y_{r_{i}, t-j, \tau}$ : portfolio 1 consists of the largest negative $e_{i, t-j, \tau} / y_{r_{i}, t-j, \tau}$ and portfolio 5 consists of the largest positive $e_{i, t-j, \tau} / y_{r_{i}, t-j, \tau}$. We expect portfolios 1 and 5 to converge faster than other portfolios. We repeat the previous procedure to produce the monthly average convergence speed for the five portfolios $\left(s_{p, m}, p=1,2, \ldots, 5\right)$.

Table 12 reports the results of the one-sided $t$-test for the null hypothesis that the monthly average convergence speed is non-negative for the five portfolios. The last two columns of the table report the paired $t$-test results if the convergence speeds of portfolio 1 (portfolio 5) is faster and more negative than portfolio 3 . The 


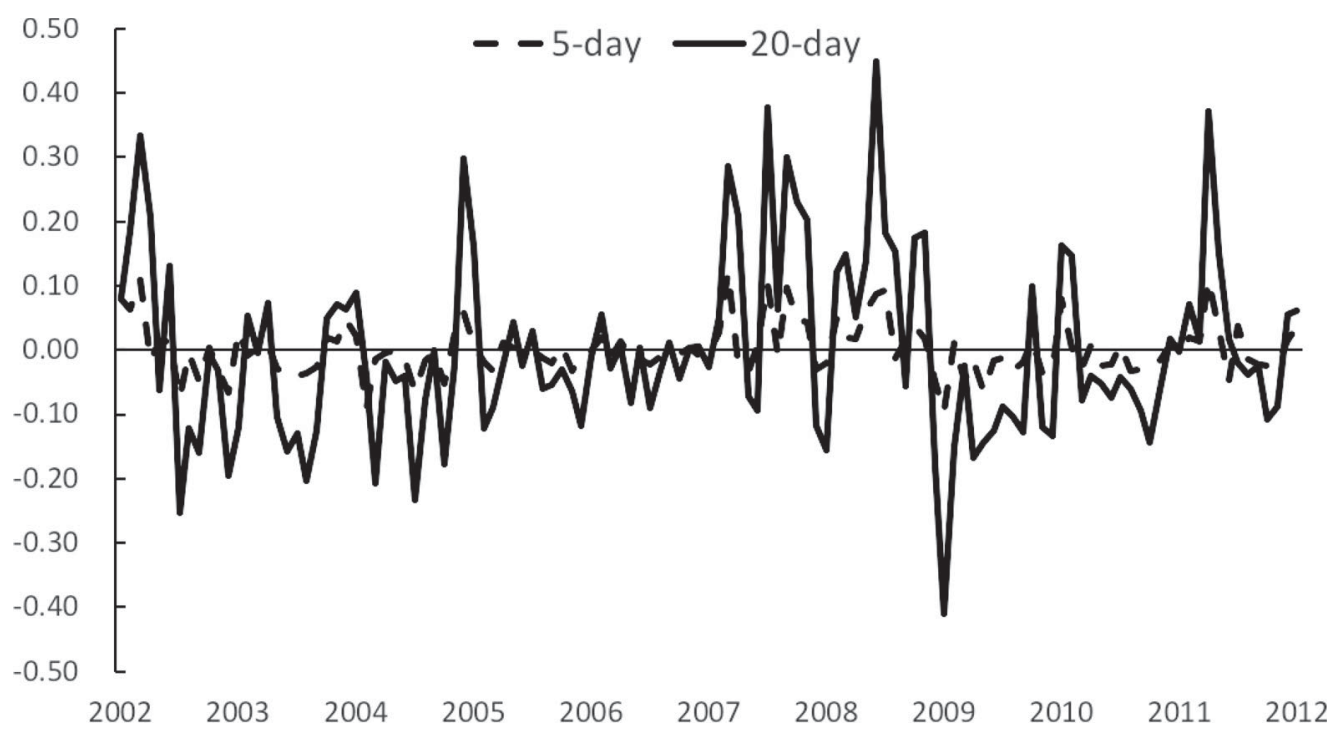

Figure 6. Monthly average convergence speed. This figure plots the monthly average convergence speed, $s_{m}$, for the 5-day and 20 -day time difference. The sample period is from May 2002 to May 2012.

Table 10. Descriptive statistics for convergence speed: 5-day intervals.

\begin{tabular}{|c|c|c|c|c|c|c|c|c|c|}
\hline \multicolumn{10}{|c|}{ Panel A: 5-day convergence speed by tenor } \\
\hline & All & 6-month & 1-year & 2-year & 3-year & 4-year & 5-year & 7-year & 10-year \\
\hline Mean & -0.000 & 0.005 & -0.001 & -0.000 & -0.000 & 0.003 & 0.000 & 0.000 & 0.000 \\
\hline Std & 0.040 & 0.067 & 0.049 & 0.044 & 0.042 & 0.039 & 0.037 & 0.036 & 0.036 \\
\hline Max & 0.125 & 0.209 & 0.166 & 0.149 & 0.135 & 0.125 & 0.120 & 0.108 & 0.138 \\
\hline Min & -0.103 & -0.176 & -0.116 & -0.126 & -0.110 & -0.101 & -0.107 & -0.101 & -0.094 \\
\hline \# Obs & 121 & 116 & 121 & 121 & 121 & 80 & 121 & 121 & 121 \\
\hline \multicolumn{10}{|c|}{ Panel B: 5-day convergence speed by tenor and rating } \\
\hline & 6-month & 1-year & 2-year & 3-year & & 4-year & 5-year & 7-year & 10-year \\
\hline AAA & -0.013 & 0.025 & 0.032 & -0.049 & & 0.016 & 0.044 & 0.074 & 0.002 \\
\hline $\mathrm{AA}$ & 0.017 & 0.003 & 0.008 & 0.002 & & 0.006 & -0.001 & -0.000 & 0.003 \\
\hline$A$ & 0.011 & 0.000 & 0.001 & -0.000 & & 0.005 & -0.000 & 0.000 & -0.000 \\
\hline BBB & 0.004 & -0.001 & -0.001 & -0.001 & & 0.002 & -0.000 & -0.001 & -0.001 \\
\hline $\mathrm{BB}$ & 0.003 & -0.003 & 0.003 & 0.003 & & 0.002 & 0.001 & 0.003 & 0.003 \\
\hline$B$ & 0.003 & 0.004 & 0.003 & 0.003 & & 0.001 & 0.004 & 0.001 & 0.004 \\
\hline C & -0.003 & 0.011 & 0.009 & 0.004 & & 0.002 & 0.004 & 0.005 & 0.001 \\
\hline
\end{tabular}

Notes: This table reports the descriptive statistics (average, standard deviation, maximum, and minimum) for the monthly average of convergence speed. The sample period is from May 2002 to May 2012 (121 months). $s_{m}$ is the monthly convergence speed of the daily calculation within the month. The calculation for convergence speed is based on Equation (9).

results are reported for all CDS contracts in our sample, as well as separately for individual rating classes. Panel A reports the results for 5-day time difference, while Panel B reports the results for 20-day time difference. The results for the 20-day difference are stronger, compared to those for the 5-day difference. Among the five portfolios, portfolio 5 with the largest positive relative deviation has the largest negative (or fastest) convergence speed on average. In most cases, the convergence speed is U-shaped; portfolio 3 has usually slower convergence speed as compared to portfolios 1 and 5. Portfolios 3 and 4 also often exhibit divergence, with the convergence speed being positive. The convergence speed for the rating $\mathrm{C}$ lacks statistical support for almost all portfolios. This suggests that high risks of the underlying and corresponding CDS contracts make individual CDS-implied hazard rates more volatile and strongly driven by the idiosyncratic firm characteristics rather than 
Table 11. Descriptive statistics for convergence speed: 20 -day intervals.

\begin{tabular}{|c|c|c|c|c|c|c|c|c|c|}
\hline \multicolumn{10}{|c|}{ Panel A: 20-day convergence speed by tenor } \\
\hline & All & 6-month & 1-year & 2-year & 3-year & 4-year & 5-year & 7-year & 10-year \\
\hline Mean & -0.002 & 0.033 & -0.006 & -0.002 & -0.002 & 0.010 & 0.000 & -0.000 & -0.001 \\
\hline Std & 0.141 & 0.309 & 0.179 & 0.154 & 0.144 & 0.136 & 0.128 & 0.123 & 0.123 \\
\hline Max & 0.449 & 1.457 & 0.569 & 0.467 & 0.458 & 0.439 & 0.453 & 0.419 & 0.394 \\
\hline Min & -0.411 & -0.634 & -0.484 & -0.416 & -0.376 & -0.382 & -0.392 & -0.397 & -0.372 \\
\hline \# Obs & 121 & 116 & 121 & 121 & 121 & 80 & 121 & 121 & 121 \\
\hline \multicolumn{10}{|c|}{ Panel B: 20-day convergence speed by tenor and rating } \\
\hline & 6-month & 1-year & 2-year & & & 4-year & 5-year & 7-year & 10-year \\
\hline AAA & -0.011 & -0.028 & 0.014 & & & 0.140 & 0.058 & 0.054 & 0.025 \\
\hline AA & -0.022 & 0.011 & 0.025 & & & 0.019 & -0.000 & -0.005 & 0.001 \\
\hline A & 0.028 & -0.006 & -0.004 & & & 0.019 & 0.001 & 0.001 & 0.001 \\
\hline BBB & -0.001 & -0.009 & -0.004 & & & 0.007 & -0.003 & -0.004 & -0.004 \\
\hline BB & 0.004 & -0.008 & 0.004 & & & 0.004 & 0.005 & 0.006 & 0.010 \\
\hline$B$ & 0.002 & 0.018 & 0.022 & & & 0.009 & 0.017 & 0.015 & 0.010 \\
\hline C & -0.034 & 0.038 & 0.013 & & & -0.001 & 0.012 & 0.010 & -0.008 \\
\hline
\end{tabular}

Notes: This table reports the descriptive statistics (average, standard deviation, maximum, and minimum) for the monthly average of convergence speed. The sample period is from May 2002 to May 2012 (121 months). $s_{m}$ is the monthly convergence speed of the daily calculation within the month. The calculation for convergence speed is based on Equation (9).

average rating-implied hazard rates. Another remarkable feature is that, although portfolio 5 (with the highest positive deviations) exhibits on average stronger convergence speed, the speed is quite volatile across rating classes and is even positive for the AA rating. The convergence speed of portfolio 1 (with the largest negative deviations) is more stable across rating classes and is always negative.

This finding reflects that CDS spreads of the relatively undervalued contracts are more likely to increase, than the spreads of overvalued contracts to decrease. This pattern sheds some light on the structure and the bargaining powers in the CDS market. The CDS is traded in the OTC market, with lower transparency relative to, e.g. the stock market. The key participants are banks, insurance companies, and hedge funds. According to Mengle (2007), banks tend to be net buyers of CDSs, whereas hedge funds and insurance companies are net sellers. Fast and stable reversion of relatively low spreads to the rating-based curves suggests that the sophisticated protection sellers are more concerned with under pricing and, thus, quickly raise their quotes in the following transactions. Protection buyers, on the contrary, are less effective in pushing for lower price for the overvalued contracts. This may be due to various reasons, including the lack of bargaining power of the protection buyers, higher demand for protection compared to its supply, or the different ways the protection sellers and buyers use the contracts. If a buyer purchases the CDS for hedging purposes, the contract is likely to be held until maturity. The frequency of trading on the buy side is lower, thus, overpricing may not be always corrected. Protection sellers, on the contrary, can sell CDS contracts on a more frequent basis, and quote a higher price, if the contract has been underpriced.

As for time variation of convergence speed, Figure 7 plots the time series of monthly average convergence speed for portfolios 1 and 5 for the 20-day time difference. The time-series plot clearly shows that although the convergence speed for these portfolios is mostly negative, it is quite volatile. The volatilities of both portfolios are similar around 13\%. We also see worse convergence during the financial crises years 2007 and 2008 (showing positive $\left.s_{5, m}\right)$.

\subsection{Convergence as a trading signal}

The convergence results in the previous section suggest a potential profit-making opportunity. Since we observe a significantly negative loading on $e_{i, t-j, \tau}$ in our panel regressions, we can predict the future movement of the 
Table 12. Convergence speed.

\begin{tabular}{|c|c|c|c|c|c|c|c|c|}
\hline & & Portfolio 1 & Portfolio 2 & Portfolio 3 & Portfolio 4 & Portfolio 5 & [1]-[3] & {$[5]-[3]$} \\
\hline \multicolumn{9}{|c|}{ Panel A: 5-day time difference } \\
\hline All & $\begin{array}{l}\text { Average } \\
t \text {-stat }\end{array}$ & $\begin{array}{c}-0.022^{* * *} \\
{[-6.38]}\end{array}$ & $\begin{array}{c}-0.023^{* * *} \\
{[-6.14]}\end{array}$ & $\begin{array}{c}-0.032^{* * *} \\
{[-7.19]}\end{array}$ & $\begin{array}{c}0.139^{* * * *} \\
{[18.05]}\end{array}$ & $\begin{array}{c}-0.068^{* * *} \\
{[-17.81]}\end{array}$ & $\begin{array}{c}0.010^{* * *} \\
{[4.16]}\end{array}$ & $\begin{array}{c}-0.036^{* * *} \\
{[-6.93]}\end{array}$ \\
\hline AAA & $\begin{array}{c}\text { Average } \\
t \text {-stat }\end{array}$ & $\begin{array}{c}-0.160^{* * *} \\
{[-2.71]}\end{array}$ & $\begin{array}{l}-0.005 \\
{[-0.11]}\end{array}$ & $\begin{array}{c}0.351^{* * * *} \\
{[5.67]}\end{array}$ & $\begin{array}{c}0.087^{*} \\
{[1.71]}\end{array}$ & $\begin{array}{c}-0.122^{* * *} \\
{[-2.75]}\end{array}$ & $\begin{array}{c}-0.516^{* * *} \\
{[-7.77]}\end{array}$ & $\begin{array}{c}-0.452^{* * *} \\
{[-7.22]}\end{array}$ \\
\hline AA & $\begin{array}{c}\text { Average } \\
t \text {-stat }\end{array}$ & $\begin{array}{c}-0.059^{* * *} \\
{[-7.64]}\end{array}$ & $\begin{array}{c}-0.037^{* * *} \\
{[-5.19]}\end{array}$ & $\begin{array}{l}-0.009 \\
{[-0.96]}\end{array}$ & $\begin{array}{c}0.069^{* * * *} \\
{[4.56]}\end{array}$ & $\begin{array}{c}0.043^{* * * *} \\
{[3.01]}\end{array}$ & $\begin{array}{c}-0.050^{* * * *} \\
{[-5.62]}\end{array}$ & $\begin{array}{c}0.052^{* * *} \\
{[3.58]}\end{array}$ \\
\hline A & $\begin{array}{c}\text { Average } \\
t \text {-stat }\end{array}$ & $\begin{array}{c}-0.037^{* * *} \\
{[-6.38]}\end{array}$ & $\begin{array}{c}-0.026^{* * *} \\
{[-4.97]}\end{array}$ & $\begin{array}{c}-0.018^{* * *} \\
{[-2.96]}\end{array}$ & $\begin{array}{c}0.096^{* * * *} \\
{[7.62]}\end{array}$ & $\begin{array}{c}-0.017^{*} \\
{[-1.89]}\end{array}$ & $\begin{array}{c}-0.020^{* * * *} \\
{[-4.33]}\end{array}$ & $\begin{array}{l}0.000 \\
{[0.03]}\end{array}$ \\
\hline BBB & $\begin{array}{c}\text { Average } \\
t \text {-stat }\end{array}$ & $\begin{array}{c}-0.019^{* * *} \\
{[-4.97]}\end{array}$ & $\begin{array}{c}-0.016^{* * *} \\
{[-4.36]}\end{array}$ & $\begin{array}{c}-0.025^{* * *} \\
{[-5.10]}\end{array}$ & $\begin{array}{c}0.109^{* * *} \\
{[11.69]}\end{array}$ & $\begin{array}{c}-0.058^{* * *} \\
{[-11.07]}\end{array}$ & $\begin{array}{c}0.006^{* *} \\
{[2.30]}\end{array}$ & $\begin{array}{c}-0.033^{* * *} \\
{[-5.27]}\end{array}$ \\
\hline BB & $\begin{array}{c}\text { Average } \\
t \text {-stat }\end{array}$ & $\begin{array}{c}-0.011^{* * *} \\
{[-2.84]}\end{array}$ & $\begin{array}{c}-0.035^{* * *} \\
{[-5.01]}\end{array}$ & $\begin{array}{c}0.065^{* * * *} \\
{[5.55]}\end{array}$ & $\begin{array}{c}0.023 * * \\
{[2.32]}\end{array}$ & $\begin{array}{c}-0.039^{* * *} \\
{[-7.92]}\end{array}$ & $\begin{array}{c}-0.076^{* * *} \\
{[-6.82]}\end{array}$ & $\begin{array}{c}-0.103^{* * *} \\
{[-7.54]}\end{array}$ \\
\hline B & $\begin{array}{c}\text { Average } \\
t \text {-stat }\end{array}$ & $\begin{array}{c}-0.013^{* * *} \\
{[-2.82]}\end{array}$ & $\begin{array}{l}-0.007 \\
{[-1.02]}\end{array}$ & $\begin{array}{l}0.004 \\
{[0.38]}\end{array}$ & $\begin{array}{c}0.076^{* * * *} \\
{[6.12]}\end{array}$ & $\begin{array}{c}-0.049 * * * \\
{[-5.02]}\end{array}$ & $\begin{array}{c}-0.017^{*} \\
{[-1.84]}\end{array}$ & $\begin{array}{c}-0.052^{* * *} \\
{[-3.15]}\end{array}$ \\
\hline C & $\begin{array}{c}\text { Average } \\
t \text {-stat }\end{array}$ & $\begin{array}{l}-0.015 \\
{[-1.36]}\end{array}$ & $\begin{array}{l}-0.009 \\
{[-0.82]}\end{array}$ & $\begin{array}{l}0.012 \\
{[0.74]}\end{array}$ & $\begin{array}{c}0.032^{*} \\
{[1.90]}\end{array}$ & $\begin{array}{l}0.001 \\
{[0.09]}\end{array}$ & $\begin{array}{l}-0.027^{*} \\
{[-1.74]}\end{array}$ & $\begin{array}{l}-0.011 \\
{[-0.44]}\end{array}$ \\
\hline \multicolumn{9}{|c|}{ Panel B: 20-day time difference } \\
\hline All & $\begin{array}{c}\text { Average } \\
t \text {-stat }\end{array}$ & $\begin{array}{c}-0.053^{* * *} \\
{[-4.48]}\end{array}$ & $\begin{array}{c}-0.060^{* * *} \\
{[-4.65]}\end{array}$ & $\begin{array}{c}-0.050^{* * *} \\
{[-3.01]}\end{array}$ & $\begin{array}{c}0.277^{* * *} \\
{[12.11]}\end{array}$ & $\begin{array}{c}-0.169 * * * \\
{[-14.01]}\end{array}$ & $\begin{array}{l}-0.003 \\
{[-0.32]}\end{array}$ & $\begin{array}{c}-0.118^{* * *} \\
{[-7.69]}\end{array}$ \\
\hline AAA & $\begin{array}{c}\text { Average } \\
t \text {-stat }\end{array}$ & $\begin{array}{c}-0.321^{* * *} \\
{[-4.34]}\end{array}$ & $\begin{array}{l}-0.004 \\
{[-0.06]}\end{array}$ & $\begin{array}{c}0.666^{* * *} \\
{[4.50]}\end{array}$ & $\begin{array}{l}0.075 \\
{[0.94]}\end{array}$ & $\begin{array}{c}-0.246^{* * *} \\
{[-2.96]}\end{array}$ & $\begin{array}{c}-0.963^{* * * *} \\
{[-5.73]}\end{array}$ & $\begin{array}{c}-0.766^{* * *} \\
{[-6.51]}\end{array}$ \\
\hline AA & $\begin{array}{c}\text { Average } \\
t \text {-stat }\end{array}$ & $\begin{array}{c}-0.112^{* * *} \\
{[-4.95]}\end{array}$ & $\begin{array}{c}-0.073^{* * *} \\
{[-3.07]}\end{array}$ & $\begin{array}{l}-0.002 \\
{[-0.06]}\end{array}$ & $\begin{array}{c}0.116^{* * *} \\
{[3.20]}\end{array}$ & $\begin{array}{c}0.094^{* *} \\
{[2.20]}\end{array}$ & $\begin{array}{c}-0.110^{* * *} \\
{[-4.65]}\end{array}$ & $\begin{array}{c}0.096^{* *} \\
{[2.32]}\end{array}$ \\
\hline A & $\begin{array}{c}\text { Average } \\
t \text {-stat }\end{array}$ & $\begin{array}{c}-0.074^{* * *} \\
{[-4.22]}\end{array}$ & $\begin{array}{c}-0.060^{* * * *} \\
{[-3.54]}\end{array}$ & $\begin{array}{l}-0.005 \\
{[-0.22]}\end{array}$ & $\begin{array}{c}0.167^{* * * *} \\
{[6.03]}\end{array}$ & $\begin{array}{c}-0.050^{* *} \\
{[-2.13]}\end{array}$ & $\begin{array}{c}-0.069^{* * * *} \\
{[-4.70]}\end{array}$ & $\begin{array}{l}-0.045 \\
{[-1.53]}\end{array}$ \\
\hline BBB & $\begin{array}{c}\text { Average } \\
t \text {-stat }\end{array}$ & $\begin{array}{c}-0.045^{* * * *} \\
{[-3.39]}\end{array}$ & $\begin{array}{c}-0.049^{* * * *} \\
{[-3.61]}\end{array}$ & $\begin{array}{c}-0.058^{* * *} \\
{[-3.19]}\end{array}$ & $\begin{array}{c}0.250^{* * * *} \\
{[9.76]}\end{array}$ & $\begin{array}{c}-0.160^{* * *} \\
{[-10.55]}\end{array}$ & $\begin{array}{l}0.013 \\
{[1.13]}\end{array}$ & $\begin{array}{c}-0.102^{* * *} \\
{[-5.52]}\end{array}$ \\
\hline BB & $\begin{array}{c}\text { Average } \\
t \text {-stat }\end{array}$ & $\begin{array}{c}-0.029^{* *} \\
{[-2.32]}\end{array}$ & $\begin{array}{c}-0.067^{* * *} \\
{[-3.54]}\end{array}$ & $\begin{array}{c}0.168^{* * *} \\
{[5.27]}\end{array}$ & $\begin{array}{l}0.003 \\
{[0.13]}\end{array}$ & $\begin{array}{c}-0.119^{* * *} \\
{[-7.19]}\end{array}$ & $\begin{array}{c}-0.197^{* * *} \\
{[-7.19]}\end{array}$ & $\begin{array}{c}-0.289^{* * *} \\
{[-8.05]}\end{array}$ \\
\hline B & $\begin{array}{c}\text { Average } \\
t \text {-stat }\end{array}$ & $\begin{array}{c}-0.030^{* *} \\
{[-2.11]}\end{array}$ & $\begin{array}{l}-0.005 \\
{[-0.25]}\end{array}$ & $\begin{array}{l}0.051 \\
{[1.64]}\end{array}$ & $\begin{array}{c}0.162^{* * * *} \\
{[5.58]}\end{array}$ & $\begin{array}{c}-0.147^{* * *} \\
{[-5.31]}\end{array}$ & $\begin{array}{c}-0.081^{* * *} \\
{[-3.24]}\end{array}$ & $\begin{array}{c}-0.183^{* * *} \\
{[-4.12]}\end{array}$ \\
\hline C & $\begin{array}{c}\text { Average } \\
t \text {-stat }\end{array}$ & $\begin{array}{l}-0.035 \\
{[-1.09]}\end{array}$ & $\begin{array}{l}-0.016 \\
{[-0.46]}\end{array}$ & $\begin{array}{l}0.049 \\
{[0.89]}\end{array}$ & $\begin{array}{l}0.044 \\
{[0.94]}\end{array}$ & $\begin{array}{l}0.007 \\
{[0.13]}\end{array}$ & $\begin{array}{l}-0.084 \\
{[-1.59]}\end{array}$ & $\begin{array}{l}-0.042 \\
{[-0.58]}\end{array}$ \\
\hline
\end{tabular}

Notes: This table reports the $t$-test results for the monthly average convergence speed of the five portfolios; portfolio 1 (5) consists of the most negative (positive) relative deviations. The sample period is from May 2002 to May 2012. Columns 1-5 test if the individual portfolio convergence speed is significantly less than zero (i.e. one-sided $t$-test), and Column 6 (Column 7) reports the result of whether convergence speed of portfolio 1 (portfolio 5) is statistically faster than portfolio 3 (i.e. $s_{1, m}$ or $s_{5, m}$ is more negative than $s_{3, m}$ ). Panel A reports the results for 5 -day time difference and Panel B reports the results for 20 -day time difference. The $t$-statistic is reported in square brackets. ${ }^{* * *},{ }^{* *}$, and ${ }^{*}$ denote, respectively, statistical significance at the $1 \%, 5 \%$, and $10 \%$ levels.

individual CDS spreads. Define the 5- or 20-day holding-period return of the CDS spreads $(k)$ as:

$$
r_{i, t, \tau}=\frac{k_{i, t, \tau}}{k_{i, t-j, \tau}}-1, \quad j=5 \text { or } 20 \text { days. }
$$

One can expect a positive holding period return if one takes a long position in a CDS with a negative $e_{i, t-j, \tau}$ at time $t-j$ and then a short position in the CDS with the same terms at time $t$ when the CDS spread moves up from time $t-j$ to $t$. Likewise, in the case of a positive $e_{i, t-j, \tau}$, a positive holding period return can be expected if one takes a short position in a CDS with a positive $e_{i, t-j, \tau}$ at time $t-j$ and a long position in the identical contract at time $t$, as the CDS spread moves down from time $t-j$ to $t$. Moreover, since the larger deviation between $h$ and $y$ has a stronger tendency to converge, more profit per trade is expected if one trades between the largest negative $e_{i, t-j, \tau}$ and the largest positive $e_{i, t-j, \tau}$.

To test this proposition, we construct the following trading strategy. Every day we identify CDS contracts with a negative (positive) relative deviation and take long (short) position. We hold these contracts for 5 (or 20) trading days, and then add to this portfolio the opposite positions in the CDSs with the same underlying firms and maturity. This portfolio is kept until the CDS maturity. On the next day, a new portfolio is formed in a 


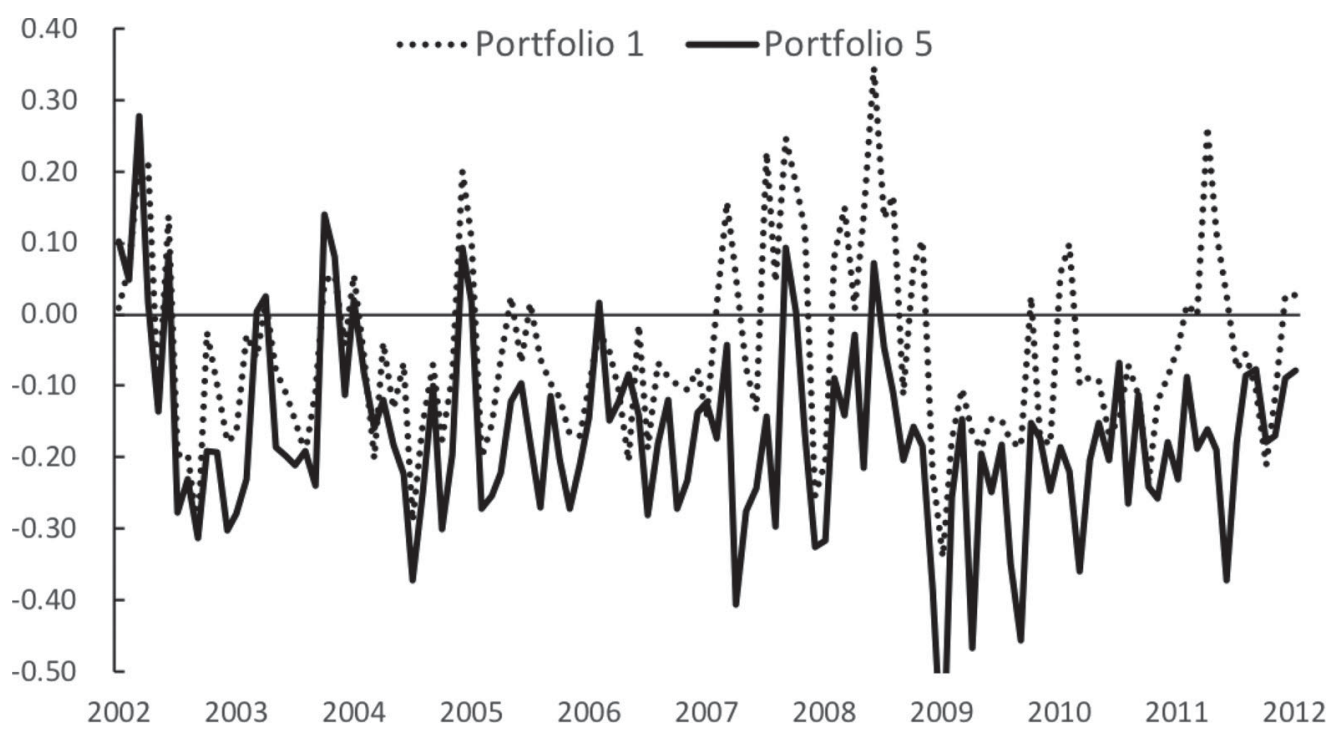

Figure 7. Portfolio monthly average convergence speed (20-day time difference). This figure plots the monthly average convergence speed, $s_{p, m}$ for portfolios 1 and 5; portfolio 1 (5) consists of the most negative (positive) relative deviations. The sample period is from May 2002 to May 2012.

similar way. We then assess the properties of the average returns an investor earns per year while following such a trading strategy.

Consider a simplified example: assume that at time $t$ we identify an underpriced (with negative relative deviation) 3-year CDS on company XYZ with a spread of $k_{t}$ bps and take a long position. After 5 days at time $t+5$ we reverse the strategy and take a short position in a 3-year CDS contract written on XYZ, with the spread being $k_{t+5}$. Nowadays CDS contracts are standardized, i.e. all the future payments happen at the end of a calendar period (e.g. end of quarter) regardless of the day when the contract was signed. Our model predicts a profit of $k_{t+5}-k_{t}$ bps per year over the next three years.

To test this strategy, we assess the performance of portfolios sorted on the relative deviations, and the performance of a long-short portfolio that longs portfolio 1 (largest negative $e_{i, t-j, \tau} / y_{r_{i}, t-j, \tau}$ ) and shorts portfolio 5 (largest positive $e_{i, t-j, \tau} / y_{r_{i}, t-j, \tau}$ ).

Table 13 reports the average returns and their standard deviations for the five portfolios and the long-short strategy for our sample, as well as the $t$-statistics for the mean difference from zero. Panel A reports the returns for 5-day holding period and Panel B reports the returns for 20-day holding period. As expected, we find a positive and highly significant mean return for portfolio 1 (3.2\% and $8.2 \%$, respectively, for 5 - and 20 -day cases), and a negative and significant mean return for portfolio $5(-0.4 \%$ and $-0.8 \%$, respectively, for 5 - and 20 -day cases). The mean returns monotonically decrease from portfolio 1 to 5, with the long-short strategy producing $3.7 \%$ and $9 \%$ for the 5- and 20-day holding periods, respectively. Note that the returns in Equation (11) are relative to the CDS spread at the beginning of the investment period. Thus, $8.2 \%$ strategy return per year is equivalent to 12.3 extra bps per year, given the average CDS spread of 150 bps.

We next examine the portfolio performance for different years, CDS maturities, rating classes, and industries. We discuss below the key findings of the sub-sample analysis; the full set of results is tabulated in Appendix 3 . The results are generally consistent with our main findings for all sub-samples, with the long-short portfolio delivering positive and highly significant average returns. The year 2002 is the only period where the average long-short portfolio returns for the 20-day trading strategy are not statistically significant, albeit the difference between portfolios 1 and 5 is still positive. At the same time, consistent with our convergence results, it is portfolio 1 (with the largest negative relative deviations) that consistently delivers positive returns, whereas the performance of portfolio 5 (with the largest positive deviations) is unstable. For example, portfolio 5 diverges in 2002 and 2008, as well as for the rating $\mathrm{C}$ and Financial sector. The corresponding trading strategy returns are all positive and 
Table 13. Portfolio holding period returns.

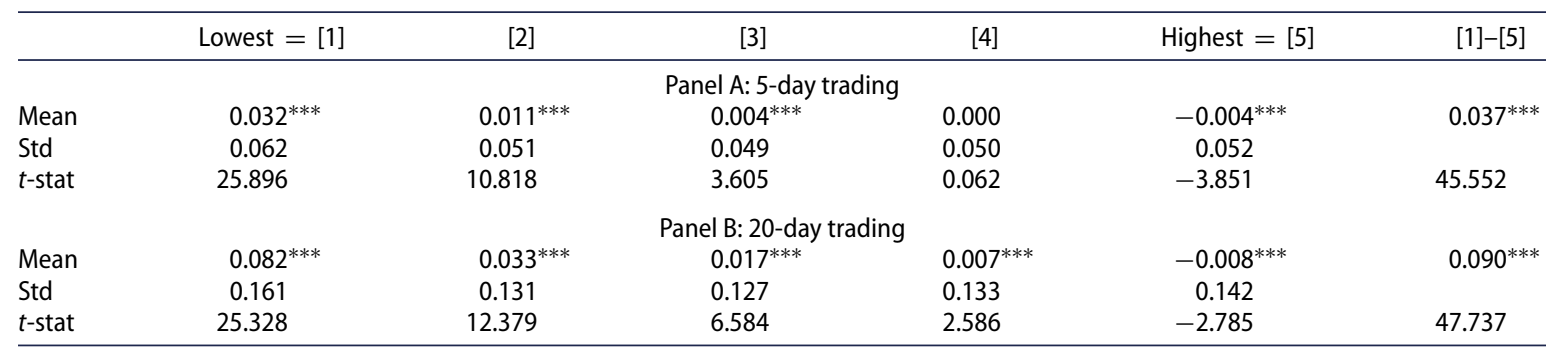

Notes: This table reports the portfolio returns for 5- and 20-day holding periods. The sample period is from May 2002 to May 2012 . The individual holding period return is defined as a ratio of CDS spreads: $r_{i, t, \tau}=k_{i, t, \tau} / k_{i, t-j, \tau}-1, j=5$ or 20 days. Each day, we sort the calculated returns into five portfolios, according to the relative deviation from its fitted CDS curve, $e_{i, t-j, \tau} / y_{r_{i}, t-j, \tau}$. Portfolio 1 has the largest negative deviation, while portfolio 5 has the largest positive deviation. The and the last column reports the difference between portfolios 1 and 5 . The $t$-statistics for the mean difference from zero are reported in the last row of each panel. ${ }^{* *},{ }^{* *}$, and ${ }^{*}$ denote, respectively, statistical significance at the $1 \%, 5 \%$, and $10 \%$ levels.

significant, whereas convergence to rating-based curves should have led to negative returns. We also do not see substantial converge for longer maturity CDSs (i.e. 4 years or longer). Here the average returns of portfolio 5 are not statistically significant. These results again highlight that investors (in particular, protection sellers) are more concerned with underpricing CDS contracts than overpricing ones. Negative deviations from the rating-based curves are quickly corrected in the market, presenting a persistent profitable investment opportunity. Positive deviations, on the contrary, are not always corrected. The revisions are especially rare during turbulent market conditions (e.g. the financial crisis) or for longer maturity CDSs, for which pricing mistakes have prolonged impact.

\subsection{Portfolio returns in the presence of transaction costs}

The portfolio performance discussed above seems quite attractive. Practically achievable returns, however, may be lower given substantial transaction costs in the CDS market. In this section we adjust the trading strategy returns to the potential transaction costs in order to more precisely quantify the achievable investor returns.

Since the actual bid-ask spreads are not available in Markit, we rely on the estimated transaction costs from the literature. Biswas, Nikolova, and Stahel (2015) suggest that in the CDS market a round trip transactions costs account for $14 \mathrm{bps}$. Similar estimate can be found in Tang and Yan (2017). Given that the average CDS spread in our sample is around $150 \mathrm{bps}$, we set the expected transaction costs to be $10 \%$ of the spread to be consistent with the literature.

The payments for a CDS contract are made periodically, until maturity of the contract, so are the cash flows generated by our trading strategy. The trading costs, however, are incurred only twice: when taking long (short) positions in the contracts the first time and then taking the opposite positions 5 or 20 trading days later. Obviously, paying 14 bps of costs for an average return of 12 bps earned for one year makes little economic sense. If this return is earned for 10 years, however, the 14 bps costs do not jeopardise the overall profitability of the strategy. Thus, in order to properly account for the impact of the transaction costs on the documented strategy returns, we need to amortize the costs over the lifetime of the contract.

To adjust the returns for transaction costs we spread the total costs of $10 \%$ of the CDS spread across two transactions (resulting in 5\% cost per transaction) and the number of protection periods $(N)$ during which the contracts are valid. For those cases in which we first take long positions in CDSs, and then short positions (e.g. portfolio 1 with negative relative deviations), we adjust the quoted CDS spreads $\left(k_{i, t-j, \tau}\right.$ and $\left.k_{i, t, \tau}\right)$ in the following way:

$$
\begin{gathered}
\tilde{k}_{i, t-j, \tau}=(1+5 \% / N) \cdot k_{i, t-j, \tau}, \\
\tilde{k}_{i, t, \tau}=(1-5 \% / N) \cdot k_{i, t, \tau},
\end{gathered}
$$


Table 14. Portfolio holding period returns: transaction costs adjusted.

\begin{tabular}{lccc}
\hline & Lowest $=[1]$ & Highest $=[5]$ & {$[1]-[5]$} \\
\hline Panel A: 5-day trading & & \\
Mean & $0.016^{* * *}$ & $0.007^{* * *}$ & $0.009^{* * *}$ \\
Std & 0.060 & 0.053 & \\
$t$-stat & 13.029 & 6.868 & 10.907 \\
Panel B: & & & \\
Mean & $0.065^{* * *}$ & 0.003 & $0.062^{* * *}$ \\
Std & 0.157 & 0.144 & \\
$t$-stat & 20.551 & 1.057 & 33.485 \\
\hline
\end{tabular}

Notes: This table reports the portfolio returns for 5 - and 20-day holding periods, after adjusting for transaction costs. The sample period is from May 2002 to May 2012. The individual holding period return is defined as a ratio of transaction costs adjusted CDS spreads: $\tilde{r}_{i, t, \tau}=\tilde{k}_{i, t, \tau} / \tilde{k}_{i, t-j, \tau}-1, j=5$ or 20 days. Each day, we sort the calculated returns into five portfolios, according to the relative deviation from its fitted CDS curve, $e_{i, t-j, \tau} / y_{r_{i}, t-j, \tau}$. Portfolio 1 has the largest negative deviation, while portfolio 5 has the largest positive deviation. The last column reports the difference between portfolios 1 and 5 . The $t$-statistics for the mean difference from zero are reported in the last row of each panel. ***,**, and ${ }^{*}$ denote, respectively, statistical significance at the $1 \%, 5 \%$, and $10 \%$ levels.

$$
\tilde{r}_{i, t, \tau}=\frac{\tilde{k}_{i, t, \tau}}{\tilde{k}_{i, t-j, \tau}}-1, \quad j=5 \text { or } 20 \text { days. }
$$

This cost adjustment implies that an investor pays more on the long leg of the trade and receives less on the short leg of the trade, leading to smaller returns. When considering portfolio 5, in which short positions should be taken first in order to achieve profits, we reverse the order of adding and subtracting $5 \%$ of the spread, in order to assure that the trading costs lead to smaller in absolute values return of portfolio $5 .{ }^{19}$

Table 14 reports the transaction cost adjusted returns for portfolios 1 and 5, as well as the performance of the long-short portfolio with 5- and 20-day trading periods. The long-short portfolio still delivers positive and significant returns, although transaction costs reduce their magnitude. The returns drop from 0.037 to 0.009 , and from 0.090 to 0.062 for 5 - and 20-day trading respectively. The transaction costs turn out to be more harmful for portfolio 5 (with overprices CDSs). The average return of this portfolio is no longer negative. Any gains from the convergence of the CDS spreads to the rating-implied curves are completely offset by the transaction costs. At the same time, the average returns on portfolio 1 remain positive and significant. Even after accounting for transaction costs, the returns for the 20-day trading strategy are as high as $6.5 \%$ per year. Betting on relatively underpriced CDS contracts remains a profitable strategy, consistent with the strong and stable convergence results for CDSs with negative deviations relative to the corresponding rating curves.

We further assess the impact of transaction costs for different years, CDS maturities, ratings, and industries. The detailed results are tabulated in Appendix 4. All the sample splits consistently indicate significant profitable opportunities for portfolio of underprices CDS contracts, whereas profitability of the trading based on overpriced contracts often disappears. Betting on spread increase of the underpriced CDSs have been especially profitable in 2008 , with the average return being $24 \%$ per year. The strategy lost money only in $2003(-4.7 \%$ average return for 20-day trading periods). We do not document any other instances of significantly negative average returns for portfolio 1 across any of the sub-samples.

\section{Robustness}

The results reported in this paper are based on the initial calibration of the rating-based hazard rates using the Nelson-Siegel model. As a robustness check, we use two simple specifications for the systematic component of CDS-implied hazard rates. The first one is the median of the hazard rates across all CDS contracts with the same maturity. The second one is the median with respect to the rating class and maturity. We re-estimate the panel regression in Equation (7), using these medians as new measures of the systematic component $y$, and the 
Table 15. Panel regression results for convergence of CDS-implied hazard rates to median hazard rates.

\begin{tabular}{|c|c|c|c|c|}
\hline & \multicolumn{2}{|c|}{ 5-day } & \multicolumn{2}{|c|}{ 20-day } \\
\hline & Model 1 & Model 2 & Model 3 & Model 4 \\
\hline \multicolumn{5}{|c|}{ Panel A: Tenor median } \\
\hline$\Delta y_{r_{i}, t, \tau}$ & & $\begin{array}{c}0.283^{* * *} \\
{[6.59]}\end{array}$ & & $\begin{array}{c}0.540^{* * * *} \\
{[6.40]}\end{array}$ \\
\hline$\Delta$ Median & $\begin{array}{c}1.254^{* * * *} \\
{[10.18]}\end{array}$ & $\begin{array}{c}0.004^{* * *} \\
{[3.67]}\end{array}$ & $\begin{array}{c}1.477^{* * *} \\
{[10.29]}\end{array}$ & $\begin{array}{c}0.013^{* * *} \\
{[2.63]}\end{array}$ \\
\hline$e_{i, t-j, \tau}$ & & $\begin{array}{c}-0.030^{* * *} \\
{[-3.41]}\end{array}$ & & $\begin{array}{c}-0.120^{* * *} \\
{[-3.65]}\end{array}$ \\
\hline$h_{r_{i}, t-j, \tau}-$ Median & $\begin{array}{c}-0.028^{* * *} \\
{[-14.34]}\end{array}$ & $\begin{array}{l}-0.005 \\
{[-0.82]}\end{array}$ & $\begin{array}{c}-0.104^{* * *} \\
{[-12.54]}\end{array}$ & $\begin{array}{l}-0.008 \\
{[-0.34]}\end{array}$ \\
\hline Adj $R$-sqr & 0.034 & 0.048 & 0.090 & 0.149 \\
\hline$\#$ Obs & $3,482,714$ & $3,482,714$ & $3,342,077$ & $3,342,077$ \\
\hline \multicolumn{5}{|c|}{ Panel B: Rating-tenor median } \\
\hline$\Delta y_{r_{i}, t, \tau}$ & & $\begin{array}{c}0.280^{* * *} \\
{[6.78]}\end{array}$ & & $\begin{array}{c}0.525^{* * * *} \\
{[7.01]}\end{array}$ \\
\hline$\Delta$ Median & $\begin{array}{c}0.613^{* * * *} \\
{[5.12]}\end{array}$ & $\begin{array}{c}0.010^{* * * *} \\
{[2.62]}\end{array}$ & $\begin{array}{c}0.771^{* * *} \\
{[6.53]}\end{array}$ & $\begin{array}{c}0.046^{* * *} \\
{[2.59]}\end{array}$ \\
\hline$e_{i, t-j, \tau}$ & & $\begin{array}{c}-0.028^{* * *} \\
{[-4.17]}\end{array}$ & & $\begin{array}{c}-0.125^{* * *} \\
{[-4.96]}\end{array}$ \\
\hline$h_{r_{i}, t-j, \tau}-$ Median & $\begin{array}{c}-0.035^{* * *} \\
{[-13.00]}\end{array}$ & $\begin{array}{l}-0.008 \\
{[-1.55]}\end{array}$ & $\begin{array}{c}-0.120^{* * *} \\
{[-9.91]}\end{array}$ & $\begin{array}{l}-0.001 \\
{[-0.04]}\end{array}$ \\
\hline Adj $R$-sqr & 0.104 & 0.050 & 0.220 & 0.156 \\
\hline \# Obs & $3,482,714$ & $3,482,714$ & $3,342,077$ & $3,342,077$ \\
\hline \multicolumn{5}{|c|}{$\begin{array}{l}\text { Notes: This table reports the panel regression results of the changes in individual CDS-implied hazard rates } \\
\text { onto changes in the median hazard date across CDSs with the same maturity (Panel A) and the same maturity } \\
\text { and rating (Panel B), as well as past deviations from the medians. The sample period is from May } 2002 \text { to } \\
\text { May } 2012 \text {. Models } 1 \text { and } 2 \text { use the time difference of one week ( } 5 \text { trading days), and Models } 3 \text { and } 4 \text { use the } \\
\text { time difference of one month ( } 20 \text { trading days). Models } 2 \text { and } 4 \text { also include the changes in the fitted values } \\
\text { of the rating-based hazard rates from the Nelson-Siegel model, and the deviations from them. The robust } \\
\text { standard errors clustered by firm are used, and the corresponding } t \text {-statistic is reported in square brackets. } \\
* * *, * *, \text { and } * \text { denote, respectively, statistical significance at the } 1 \%, 5 \% \text {, and } 10 \% \text { levels. }\end{array}$} \\
\hline
\end{tabular}

deviations from them as $e$. The results in Table 15 indicate that CDS-implied hazard rates also converge to the median hazard rates. These results confirm the importance of the systematic information for CDS pricing. When the convergence to the Nelson-Siegel-based rating component and the median is considered jointly, we cannot find any evidence of the convergence towards the median, whereas we still find significant convergence towards the Nelson-Siegel-based hazard rates. The loadings on the deviations from the fitted values are negative and significant for both 5- and 20-day trading periods, but they are not significant for deviations from the median. Thus, we conclude that our approach of using the Nelson-Sigel model to back out the systematic component allows us to extract a stronger convergence signal, as compared to using median values.

\section{Conclusion}

In this paper, we use individual senior unsecured tier CDS spreads of U.S. firms from May 2002 to May 2012 and construct daily rating-based hazard rate curves using the Nelson-Siegel model. These rating curves are shown to be good proxies for the long-run mean of CDS-implied hazard rates. The individual deviations from these curves are not persistent, and the individual CDS-implied hazard rates converge towards the rating curves already over 5- and 20-day periods. Moreover, the larger the deviation is, the faster the hazard rate converges to the fitted curve. Hence, by taking a long position in the portfolio of CDSs with the largest negative deviation and a short position in the portfolio of CDSs with the largest positive deviation, one can generate an average profit of 3.7\% (9\%) per year for the 5-day (20-day) trading strategy. The convergence results are stronger and more stable for relatively undervalued CDSs. This suggests a prompt reaction on the side of protection sellers, who revise CDS spreads upwards trying to avoid underpricing. 
The rating-based CDS curves, proposed in this paper, provide long-run means for CDS-implied hazard rates and, hence, CDS spreads themselves, across rating classes and maturities. Thus, they are potentially useful in credit risk management. The documented convergence of CDS spreads towards the fitted curves over time has two implications. First, on a theoretical level, it suggests that other factors that impact CDS spreads in the shortrun, such as liquidity or shocks to supply/demand, do not have persistent impact on top of anything which is already incorporated into the average CDS spread within each rating class. Second, on a practical level, the deviations from the fitted curves serve as trading signals, indicating exploitable profit-making opportunities in the CDS market, which are still pronounced even after accounting for transitions costs. The results are robust to changes in sample periods, CDS maturities, and industries.

\section{Notes}

1. 'CDSs activity heats up', Financial Times, https://www.ft.com/content/c47dce8e-ca9f-11e5-be0b-b7ece4e953a0.

2. The accuracy of the default probability estimate is important here. The potential models span the classical structural models such as Merton (1974), and its extensions including, a flexible corporate debt structure and default date in Leland and Toft (1996), or creditor-shareholder bargaining at firm's default (Fan and Sundaresan 2000; Ericsson and Renault 2006), as well as the reducedform models including, for example, Altman (1968), Jarrow, Lando, and Turnbull (1997), Duffie and Singleton (1999), and Campbell, Hilscher, and Szilagyi (2008) among others.

3. For example, firms' ratings still can be used to determine the capital requirements in banks under the Basel III framework https://www.bis.org/bcbs/publ/d424.htm.

4. For instance, GFI/FENICS constructs single-name CDS spreads using Hull-White methodology; Markit also provides various smoothed credit curves (such as single-name CDS curves and sector credit curves) by pair-wise interpolating individual CDS spreads. See the Markit (2012, June) user manual for more information. In practice, credit curves are often used by clients to analyze the delta risk of the CDS spreads (CV01) or to assess the CDS spreads for other tenors. Credit curve providers might not consider the term structure of the CDS spreads, or provide the accuracy test for these curves.

5. Empirical literature suggests multiple individual CDS factors that impact the spreads. Das, Hanouna, and Sarin (2009) find that both accounting-based and market-based credit information are important drivers of CDS spreads. Several studies find that CDS illiquidity increases CDS spreads. See, for example, Tang and Yan (2007), Corò, Dufour, and Varotto (2013), and Das and Hanouna (2009) among others.

6. See Longstaff, Mithal, and Neis (2005).

7. Markit requires the data providers to report the quote for CDS spreads and the corresponding recovery rate at the individual entity level.

8. One alternative to our implied hazard rate would be the forward hazard rate, such that each CDS of the same underlying is priced using different forward hazard rates at different periods. The empirical challenge is that such forward hazard rates are inherently 'unsmooth', subject to a very high level of noise and estimation errors.

9. In a later section, we show that our approach is superior to the median in prediction for CDS movement.

10. The times to maturity of the CDSs in Markit are 6 months, 1, 2, 3, 4, 5, 7, 10, 15, 20, and 30 years. We select the CDSs with time to maturity 10 years or less, because these CDSs are traded more frequently.

11. See Markit (2012) for more details on the data cleaning process.

12. See Hull, Predescu, and White (2004) for further explanation.

13. See, e.g. Moody's Investor Service, Annual Default Study: Corporate Default and Recovery Rates, 1920-2015 https://www. moodys.com/researchdocumentcontentpage.aspx?docid = PBC_1018455.

14. Further looking at the time-series dynamics of CDS spreads for different maturities, we find that the pattern is almost identical for all maturities, with the only difference that spreads of shorter-term CDS contracts are generally smaller than those of longerterm contracts.

15. Note that since there is no active secondary market for CDS contracts, the composite spreads reported by Markit represent the spreads of newly issued contracts with set maturities from 6 months to 10 years.

16. Note that the reported minimum for 6 -months fitted values is negative of $-2.49 \mathrm{bps}$. This is a single negative observation in our sample, obtained for an AAA curve on 25 July 2006. The reason for such result is poor quality of calibration, as on that date there are only two observations to calibrate four parameters. There are no other instances of negative fitted values in our sample.

17. Further looking at the median residuals, we find that they are closer to zero in absolute values, although remain negative.

18. Further inspection of the annual variation of the convergence speed for this rating class finds convergence in most of years, except during financial crisis in 2008 and 2009.

19. We apply the transaction costs only to portfolios 1 and 5 , since the trading direction in these portfolios is clearly determined, and we attempt to verify if the performance of the long-short portfolio remains positive after inclusion of transaction costs. 


\section{Disclosure statement}

No potential conflict of interest was reported by the authors.

\section{References}

Altman, E. I. 1968. "Financial Ratios, Discriminant Analysis and the Prediction of Corporate Bankruptcy." The Journal of Finance 23 (4): 589-609.

Altman, E. I., and H. A. Rijken. 2004. "How Rating Agencies Achieve Rating Stability.” Journal of Banking and Finance 28 (11): 2679-2714.

Anderson, M. 2017. "What Drives the Commonality between Credit Default Swap Spread Changes?" Journal of Financial and Quantitative Analysis 52 (1): 243-275.

Bai, J., and L. Wu. 2016. “Anchoring Credit Default Swap Spreads to Firm Fundamentals.” Journal of Financial and Quantitative Analysis 51 (5): 1521-1543.

Biswas, G., S. Nikolova, and C. W. Stahel. 2015. “The Transaction Costs of Trading Corporate Credit.” Working paper.

Campbell, J. Y., J. Hilscher, and J. Szilagyi. 2008. “In Search of Distress Risk.” Journal of Finance 63: 2899-2939.

Carr, P., and L. Wu. 2011. "A Simple Robust Link between American Puts and Credit Protection." Review of Financial Studies 24 (2): 473-505.

Chava, S., R. Ganduri, and C. Ornthanalai. 2016. “Are Credit Ratings Still Relevant?” Working Paper.

Conrad, J., R. Dittmar, and A. Hameed. 2011. Cross-market and Cross-firm Effects in Implied Default Probabilities and Recovery Values." Working Paper.

Corò, F., A. Dufour, and S. Varotto. 2013. "Credit and Liquidity Components of Corporate CDS Spreads." Journal of Banking \& Finance 37: 5511-5525.

Das, S. R., and P. Hanouna. 2009. "Hedging Credit: Equity Liquidity Matters.” Journal of Financial Intermediation 18: 112-123.

Das, S. R., P. Hanouna, and A. Sarin. 2009. “Accounting-based Versus Market-based Cross-sectional Models of CDS Spreads." Journal of Banking \& Finance 33 (4): 719-730.

Doshi, H., J. Ericsson, K. Jacobs, and S. M. Turnbull. 2013. "Pricing Credit Default Swaps with Observable Covariates.” Review of Financial Studies 26 (8): 2049-2094.

Duffie, D., and K. J. Singleton. 1999. “Modeling Term Structures of Defaultable Bonds.” Review of Financial Studies 12 (4): 687-720.

Ericsson, J., and O. Renault. 2006. "Liquidity and Credit Risk." The Journal of Finance 61 (5): 2219-2250.

Fan, H., and S. M. Sundaresan. 2000. "Debt Valuation, Renegotiation, and Optimal Dividend Policy.” Review of Financial Studies 13 (4): 1057-1099.

Finnerty, J. D., C. D. Miller, and R.-R. Chen. 2013. “The Impact of Credit Rating Announcements on Credit Default Swap Spreads.” Journal of Banking \& Finance 37 (6): 2011-2030.

Galil, K., O. M. Shapir, D. Amiram, and U. Ben-Zion. 2014. “The Determinants of CDS Spreads.” Journal of Banking \& Finance 41: 271-282.

Hart, O., and L. Zingales. 2011. “A New Capital Regulation for Large Financial Institutions.” American Law and Economics Review 13 (2): 453-490.

Hu, G. X., J. Pan, and J. Wang. 2013. “Noise as Information for Illiquidity.” Journal of Finance 68: 2341-2382.

Hull, J., M. Predescu, and A. White. 2004. "The Relationship between Credit Default Swap Spreads, Bond Yields, and Credit Rating Announcements." Journal of Banking \& Finance 28 (11): 2789-2811.

Hull, J. C., and A. D. White. 2001. "Valuing Credit Default Swaps II: Modeling Default Correlations." The Journal of Derivatives 8 (3): 12-21.

Jarrow, R. A., D. Lando, and S. M. Turnbull. 1997. “A Markov Model for the Term Structure of Credit Risk Spreads.” Review of Financial studies 10 (2): 481-523.

Leland, H. E., and K. B. Toft. 1996. "Optimal Capital Structure, Endogenous Bankruptcy, and the Term Structure of Credit Spreads." Journal of Finance 51: 987-1019.

Lin, M.-T., O. Kolokolova, and S.-H. Poon. 2016. Systematic and Firm-specifc Risks of CDS Spreads: Credit and Liquidity under Scrutiny." Working Paper.

Löffler, G. 2004. “An Anatomy of Rating through the Cycle.” Journal of Banking and Finance 28 (3): 695-720.

Löffler, G. 2007. “The Complementary Nature of Ratings and Market-based Measures of Default Risk.” The Journal of Fixed Income 17 (1): 38-47.

Löffler, G. 2013. “Can Rating Agencies Look through the Cycle?” Review of Quantitative Finance and Accounting 40 (4): $623-646$.

Longstaff, F. A., S. Mithal, and E. Neis. 2005. "Corporate Yield Spreads: Default Risk or Liquidity? New Evidence from the Credit Default Swap Market.” Journal of Finance 60: 2213-2253.

Longstaff, F. A., J. Pan, L. H. Pedersen, and K. J. Singleton. 2011. “How Sovereign is Sovereign Credit Risk?” American Economic Journal: Macroeconomics 3 (2): 75-103.

Markit. 2012, June. User Guide CDS \& Bonds. London: Markit.

Mengle, D. 2007. “Are all Credit Default Swap Databases Equal?” Economic Review - Federal Reserve Bank of Atlanta 92 (4): 1-24.

Merton, R. C. 1974. “On the Pricing of Corporate Debt: The Risk Structure of Interest Rates.” Journal of Finance 29: 449-470. 
Micu, M., E. M. Remolona, and P. D. Wooldridge. 2006. “The Price Impact of Rating Announcements: Which Announcements Matter?" Working paper.

Nelson, C. R., and A. F. Siegel. 1987. “Parsimonious Modeling of Yield Curves.” Journal of Business 60: 473-489.

Norden, L., and M. Weber. 2004. "Informational Efficiency of Credit Default Swap and Stock Markets: The Impact of Credit Rating Announcements.” Journal of Banking \& Finance 28 (11): 2813-2843.

Qiu, J., and F. Yu. 2012. "Endogenous Liquidity in Credit Derivatives.” Journal of Financial Economics 103 (3): $611-631$.

Tang, D. Y., and H. Yan. 2007. "Liquidity and Credit Default Swap Spreads.” Working Paper.

Tang, D. Y., and H. Yan. 2013. "What Moves CDS Spreads?” Working paper.

Tang, D. Y., and H. Yan. 2017. "Understanding Transactions Prices in the Credit Default Swaps Market.” Journal of Financial Markets 32: 1-27.

\section{Appendix 1. Robustness checks for convergence of CDS-implied hazard rates to their rating curves}

In this section, we provide the CDS-implied hazard rate convergence results for different years (Table A1), CDS maturities (Table A2), ratings (Table A3), and industries (Table A4). We use a panel regression as specified in Equation (7). Overall, the results are consistent with the main results reported in the body of the paper.

\section{Appendix 2. Derivation of the impulse-response function}

In this section we present the intuitive derivation of the impulse-response function used in Section 6.1.

Consider the model: $\Delta h_{t}=\beta_{1} \Delta y_{t}+\beta_{2} e_{t-1}$, where $h_{t}=y_{t}+e_{t}$. Therefore,

$$
\begin{aligned}
e_{t-1} & =\frac{1}{\beta_{2}} \Delta h_{t}-\frac{\beta_{1}}{\beta_{2}} \Delta y_{t} \\
e_{t-1} & =h_{t-1}-y_{t-1} .
\end{aligned}
$$

\begin{tabular}{|c|c|c|c|c|c|c|}
\hline & \multicolumn{3}{|c|}{ Panel A: 5-day trading } & \multicolumn{3}{|c|}{ Panel B: 20-day trading } \\
\hline & $\beta_{2}$ & Adj $R$-sqr & \# Obs & $\beta_{2}$ & Adj $R$-sqr & \# Obs \\
\hline Y2002 & $\begin{array}{c}-0.188^{* * *} \\
{[-3.22]}\end{array}$ & 0.102 & 85,369 & $\begin{array}{c}-0.501^{* * *} \\
{[-6.58]}\end{array}$ & 0.260 & 72,455 \\
\hline Y2003 & $\begin{array}{c}-0.100^{* * *} \\
{[-5.19]}\end{array}$ & 0.073 & 141,210 & $\begin{array}{c}-0.313^{* * *} \\
{[-6.79]}\end{array}$ & 0.273 & 128,339 \\
\hline Y2004 & $\begin{array}{c}-0.048^{* * *} \\
{[-3.77]}\end{array}$ & 0.030 & 217,123 & $\begin{array}{c}-0.163^{* * *} \\
{[-3.90]}\end{array}$ & 0.098 & 203,133 \\
\hline Y2005 & $\begin{array}{c}-0.061^{* * *} \\
{[-3.06]}\end{array}$ & 0.032 & 314,864 & $\begin{array}{c}-0.193^{* * *} \\
{[-3.96]}\end{array}$ & 0.117 & 293,106 \\
\hline Y2006 & $\begin{array}{c}-0.067^{* *} \\
{[-2.03]}\end{array}$ & 0.032 & 390,680 & $\begin{array}{c}-0.188^{* *} \\
{[-2.30]}\end{array}$ & 0.086 & 373,290 \\
\hline Y2007 & $\begin{array}{c}-0.034^{* * *} \\
{[-4.46]}\end{array}$ & 0.038 & 438,783 & $\begin{array}{c}-0.110^{* * *} \\
{[-5.05]}\end{array}$ & 0.104 & 423,541 \\
\hline Y2008 & $\begin{array}{c}-0.064^{* * *} \\
{[-4.63]}\end{array}$ & 0.115 & 423,921 & $\begin{array}{c}-0.179 * * * \\
{[-4.76]}\end{array}$ & 0.208 & 415,593 \\
\hline Y2009 & $\begin{array}{c}-0.088^{* * *} \\
{[-6.04]}\end{array}$ & 0.087 & 422,318 & $\begin{array}{c}-0.313^{* * *} \\
{[-7.80]}\end{array}$ & 0.248 & 408,019 \\
\hline Y2010 & $\begin{array}{c}-0.092^{* * *} \\
{[-10.78]}\end{array}$ & 0.085 & 441,800 & $\begin{array}{c}-0.311^{* * *} \\
{[-6.13]}\end{array}$ & 0.230 & 432,824 \\
\hline Y2011 & $\begin{array}{c}-0.082^{* * *} \\
{[-4.84]}\end{array}$ & 0.067 & 432,428 & $\begin{array}{c}-0.224^{* * *} \\
{[-4.97]}\end{array}$ & 0.197 & 422,277 \\
\hline Y2012 & $\begin{array}{c}-0.126^{*} \\
{[-1.95]}\end{array}$ & 0.060 & 174,218 & $\begin{array}{c}-0.356^{* *} \\
{[-2.47]}\end{array}$ & 0.211 & 169,500 \\
\hline
\end{tabular}

Table A1. Panel regression results for convergence of CDS-implied hazard rates to their rating curves: year-by-year.

Notes: This table reports the panel regression results of the changes in individual CDS-implied hazard rates onto changes in the rating-implied hazard rates, as well as past deviation, estimated for individual years. The sample period is from May 2002 to May 2012. Panel A uses time difference of one week ( 5 trading days), and Panel B uses time difference of one month ( 20 trading days). We only report the $\beta_{2}$ coefficient (the loading on $e_{i, t-j, \tau}$ ) to conserve space. The robust standard errors clustered by firm are used, and the corresponding $t$-statistic is reported in square brackets. ${ }^{* * *},{ }^{* *}$, and ${ }^{*}$ denote, respectively, statistical significance at the $1 \%, 5 \%$, and $10 \%$ levels. 
Table A2. Panel regression results for convergence of CDS-implied hazard rates to their rating curves: by CDS maturity.

\begin{tabular}{|c|c|c|c|c|c|c|}
\hline & \multicolumn{3}{|c|}{ Panel A: 5-day trading } & \multicolumn{3}{|c|}{ Panel B: 20-day trading } \\
\hline & $\beta_{2}$ & Adj $R$-sqr & \# Obs & $\beta_{2}$ & Adj $R$-sqr & \# Obs \\
\hline 6-month & $\begin{array}{c}-0.059 * * * \\
{[-4.91]}\end{array}$ & 0.048 & 285,912 & $\begin{array}{c}-0.189 * * * \\
{[-5.94]}\end{array}$ & 0.167 & 256,130 \\
\hline 1-year & $\begin{array}{c}-0.037^{* * *} \\
{[-11.30]}\end{array}$ & 0.050 & 445,080 & $\begin{array}{c}-0.127^{* * *} \\
{[-7.69]}\end{array}$ & 0.154 & 425,250 \\
\hline 2-year & $\begin{array}{c}-0.038^{* * *} \\
{[-7.54]}\end{array}$ & 0.056 & 449,475 & $\begin{array}{c}-0.132^{* * *} \\
{[-8.84]}\end{array}$ & 0.171 & 432,359 \\
\hline 3-year & $\begin{array}{c}-0.033^{* * *} \\
{[-9.35]}\end{array}$ & 0.057 & 484,095 & $\begin{array}{c}-0.123^{* * *} \\
{[-10.03]}\end{array}$ & 0.164 & 468,327 \\
\hline 4-year & $\begin{array}{c}-0.032^{* * *} \\
{[-5.33]}\end{array}$ & 0.062 & 343,285 & $\begin{array}{c}-0.124^{* * *} \\
{[-6.09]}\end{array}$ & 0.171 & 332,711 \\
\hline 5-year & $\begin{array}{c}-0.032^{* * *} \\
{[-6.55]}\end{array}$ & 0.046 & 520,496 & $\begin{array}{c}-0.124 * * * \\
{[-8.42]}\end{array}$ & 0.140 & 504,311 \\
\hline 7-year & $\begin{array}{c}-0.031^{* * *} \\
{[-6.26]}\end{array}$ & 0.050 & 481,678 & $\begin{array}{c}-0.123^{* * *} \\
{[-6.66]}\end{array}$ & 0.140 & 466,226 \\
\hline 10-year & $\begin{array}{c}-0.034^{* * *} \\
{[-6.12]}\end{array}$ & 0.040 & 472,693 & $\begin{array}{c}-0.134^{* * *} \\
{[-6.64]}\end{array}$ & 0.131 & 456,763 \\
\hline
\end{tabular}

Notes: This table reports the panel regression results of the changes in individual CDS-implied hazard rates onto changes in the rating-implied hazard rates, as well as past deviation, estimated for different CDS maturities. The sample period is from May 2002 to May 2012 . Panel A uses time difference of one week ( 5 trading days), and Panel B uses time difference of one month ( 20 trading days). We only report the $\beta_{2}$ coefficient (the loading on $e_{i, t-j, \tau}$ ) to conserve space. The robust standard errors clustered by firm are used, and the corresponding $t$-statistic is reported in square brackets. ${ }^{* * *}, * *$, and $*$ denote, respectively, statistical significance at the $1 \%, 5 \%$, and $10 \%$ levels.

Table A3. Panel regression results for convergence of CDS-implied hazard rates to their rating curves: by rating.

\begin{tabular}{|c|c|c|c|c|c|c|}
\hline & \multicolumn{3}{|c|}{ Panel A: 5-day trading } & \multicolumn{3}{|c|}{ Panel B: 20-day trading } \\
\hline & $\beta_{2}$ & Adj $R$-sqr & \# Obs & $\beta_{2}$ & Adj $R$-sqr & \#Obs \\
\hline AAA & $\begin{array}{c}-0.100^{* * *} \\
{[-4.82]}\end{array}$ & 0.297 & 26,025 & $\begin{array}{c}-0.278^{* * *} \\
{[-7.02]}\end{array}$ & 0.459 & 23,964 \\
\hline AA & $\begin{array}{l}0.027 \\
{[1.62]}\end{array}$ & 0.068 & 109,150 & $\begin{array}{l}0.033 \\
{[0.95]}\end{array}$ & 0.132 & 104,961 \\
\hline A & $\begin{array}{c}-0.021^{* * *} \\
{[-8.07]}\end{array}$ & 0.118 & 750,156 & $\begin{array}{c}-0.077^{* * *} \\
{[-6.61]}\end{array}$ & 0.206 & 721,945 \\
\hline BBB & $\begin{array}{c}-0.034^{* * *} \\
{[-4.69]}\end{array}$ & 0.083 & $1,629,846$ & $\begin{array}{c}-0.099^{* * * *} \\
{[-9.77]}\end{array}$ & 0.193 & $1,572,053$ \\
\hline BB & $\begin{array}{c}-0.031^{* * *} \\
{[-7.21]}\end{array}$ & 0.038 & 517,047 & $\begin{array}{c}-0.081^{* * *} \\
{[-5.08]}\end{array}$ & 0.109 & 491,154 \\
\hline B & $\begin{array}{c}-0.039^{* * *} \\
{[-5.69]}\end{array}$ & 0.064 & 369,635 & $\begin{array}{c}-0.152^{* * *} \\
{[-5.71]}\end{array}$ & 0.169 & 352,521 \\
\hline C & $\begin{array}{c}-0.033^{* * *} \\
{[-3.37]}\end{array}$ & 0.038 & 80,855 & $\begin{array}{c}-0.137^{* * *} \\
{[-6.97]}\end{array}$ & 0.139 & 75,479 \\
\hline
\end{tabular}

Notes: This table reports the panel regression results of the changes in individual CDS-implied hazard rates onto changes in the rating-implied hazard rates, as well as past deviation, estimated for different rating classes of the underlying. The sample period is from May 2002 to May 2012. Panel A uses time difference of one week ( 5 trading days), and Panel B uses time difference of one month (20 trading days). We only report the $\beta_{2}$ coefficient (the loading on $e_{i, t-j, \tau}$ ) to conserve space. The robust standard errors clustered by firm are used, and the corresponding $t$-statistic is reported in square brackets. ${ }^{* * *}, * *$, and $*$ denote, respectively, statistical significance at the $1 \%, 5 \%$, and $10 \%$ levels.

Solving the system of equations above, we obtain:

$$
h_{t}=\left(1+\beta_{2}\right) h_{t-1}+\beta_{1} y_{t}-\left(\beta_{1}+\beta_{2}\right) y_{t-1}
$$

Consider a shock $e_{0}=1$ at time $t=0$. Assuming $y_{0}=0, h_{0}=y_{0}+e_{0}=1$. Then,

$$
h_{1}=\left(1+\beta_{2}\right) h_{0}+\beta_{1} y_{1}-\left(\beta_{1}+\beta_{2}\right) y_{0}=\left(1+\beta_{2}\right)+\beta_{1} y_{1}
$$


Table A4. Panel regression results for convergence of CDS-implied hazard rates to their rating curves: by industry.

\begin{tabular}{|c|c|c|c|c|c|c|}
\hline & \multicolumn{3}{|c|}{ Panel A: 5-day trading } & \multicolumn{3}{|c|}{ Panel B: 20-day trading } \\
\hline & $\beta_{2}$ & Adj $R$-sqr & \# Obs & $\beta_{2}$ & Adj $R$-sqr & \# Obs \\
\hline Basic materials & $\begin{array}{c}-0.036^{* * *} \\
{[-4.62]}\end{array}$ & 0.033 & 273,506 & $\begin{array}{c}-0.104^{* * *} \\
{[-4.87]}\end{array}$ & 0.114 & 261,178 \\
\hline Consumer goods & $\begin{array}{l}-0.028 \\
{[-1.33]}\end{array}$ & 0.050 & 644,603 & $\begin{array}{c}-0.140^{*} \\
{[-1.90]}\end{array}$ & 0.145 & 619,241 \\
\hline Consumer services & $\begin{array}{c}-0.038^{* * *} \\
{[-7.64]}\end{array}$ & 0.049 & 614,689 & $\begin{array}{c}-0.127^{* * *} \\
{[-5.69]}\end{array}$ & 0.159 & 590,911 \\
\hline Energy & $\begin{array}{c}-0.022^{* * *} \\
{[-4.98]}\end{array}$ & 0.105 & 345,310 & $\begin{array}{c}-0.085^{* * *} \\
{[-5.39]}\end{array}$ & 0.206 & 332,339 \\
\hline Financials & $\begin{array}{l}-0.033 \\
{[-1.19]}\end{array}$ & 0.031 & 65,662 & $\begin{array}{c}-0.089^{*} \\
{[-1.84]}\end{array}$ & 0.110 & 63,565 \\
\hline Healthcare & $\begin{array}{c}-0.009^{* * *} \\
{[-4.22]}\end{array}$ & 0.057 & 265,932 & $\begin{array}{c}-0.029^{* * *} \\
{[-4.13]}\end{array}$ & 0.133 & 252,949 \\
\hline Industrials & $\begin{array}{c}-0.042^{* * *} \\
{[-10.79]}\end{array}$ & 0.057 & 582,068 & $\begin{array}{c}-0.133^{* * *} \\
{[-14.86]}\end{array}$ & 0.161 & 561,047 \\
\hline Technology & $\begin{array}{c}-0.033^{* * *} \\
{[-4.49]}\end{array}$ & 0.084 & 313,076 & $\begin{array}{c}-0.161^{* * *} \\
{[-4.22]}\end{array}$ & 0.257 & 298,843 \\
\hline Telecommunications services & $\begin{array}{l}-0.018 \\
{[-1.41]}\end{array}$ & 0.011 & 82,260 & $\begin{array}{l}-0.042 \\
{[-1.41]}\end{array}$ & 0.030 & 78,754 \\
\hline Utilities & $\begin{array}{c}-0.043^{* *} \\
{[-2.50]}\end{array}$ & 0.054 & 275,665 & $\begin{array}{c}-0.112^{* * *} \\
{[-6.84]}\end{array}$ & 0.136 & 264,881 \\
\hline
\end{tabular}

Notes: This table reports the panel regression results of the changes in individual CDS-implied hazard rates onto changes in the rating-implied hazard rates, as well as past deviation, estimated for different industries. The sample period is from May 2002 to May 2012. Panel A uses time difference of one week (5 trading days), and Panel B uses time difference of one month (20 trading days). We only report the $\beta_{2}$ coefficient (the loading on $e_{i, t-j, \tau}$ ) to conserve space. The robust standard errors clustered by firm are used, and the corresponding $t$-statistic is reported in square brackets. ${ }^{* * *}, * *$, and ${ }^{*}$ denote, respectively, statistical significance at the $1 \%, 5 \%$, and $10 \%$ levels.

On the next step, $h_{2}$ can be expressed using Equation (A.1): $h_{2}=\left(1+\beta_{2}\right) h_{1}+\beta_{1} y_{2}-\left(\beta_{1}+\beta_{2}\right) y_{1}$. Substituting $h_{1}$ by its expression in Equation (A.2), we obtain

$$
\begin{aligned}
h_{2} & =\left(1+\beta_{2}\right)\left[\left(1+\beta_{2}\right)+\beta_{1} y_{1}\right]+\beta_{1} y_{2}-\left(\beta_{1}+\beta_{2}\right) y_{1} \\
& =\left(1+\beta_{2}\right)^{2}+\beta_{1} y_{2}+\left(\beta_{1}-1\right) \beta_{2} y_{1} .
\end{aligned}
$$

Following the same procedure, we can derive the value for $h_{3}$,

$$
h_{3}=\left(1+\beta_{2}\right)^{3}+\beta_{1} y_{3}+\left(\beta_{1}-1\right) \beta_{2} y_{2}+\left(\beta_{1}-1\right)\left(1+\beta_{2}\right) \beta_{2} y_{1} .
$$

Iterating the process further, the general form for $h_{t}$ can be expressed as:

$$
h_{t}=\left(1+\beta_{2}\right)^{t}+\sum_{i=1}^{t} B\left(\beta_{1}, \beta_{2}\right) y_{i},
$$

where $B\left(\beta_{1}, \beta_{2}\right)$ is the function of $\beta_{1}$ and $\beta_{2}$.

Setting $y_{i}=0$ for all $i$, we obtain the equation used in Section 6.1 of the main body of the paper:

$$
h_{t}=\left(1+\beta_{2}\right)^{t} \text {. }
$$

\section{Appendix 3. Trading strategy across different types of CDSs and time periods}

In this section we tabulate the trading strategy results for different years (Table A5), CDS maturities (Table A6), ratings (Table A7), and industries (Table A8). We use the past relative deviation $\left(e_{i, t-j, \tau} / y_{r_{i}, t-j, \tau}\right)$ to sort CDS contracts into quintile portfolios. The portfolio returns are reported for 5-day and 20-day holding periods.

\section{Appendix 4. Transaction cost adjusted trading strategy across different types of CDSs and time periods}

In this section we tabulate the trading strategy results after adjusting for transaction costs for different years (Table A9), CDS maturities (Table A10), ratings (Table A11), and industries (Table A12). We use the past relative deviation $\left(e_{i, t-j, \tau} / y_{r_{i}, t-j, \tau}\right)$ to sort portfolio 
Table A5. Portfolio returns: year by year.

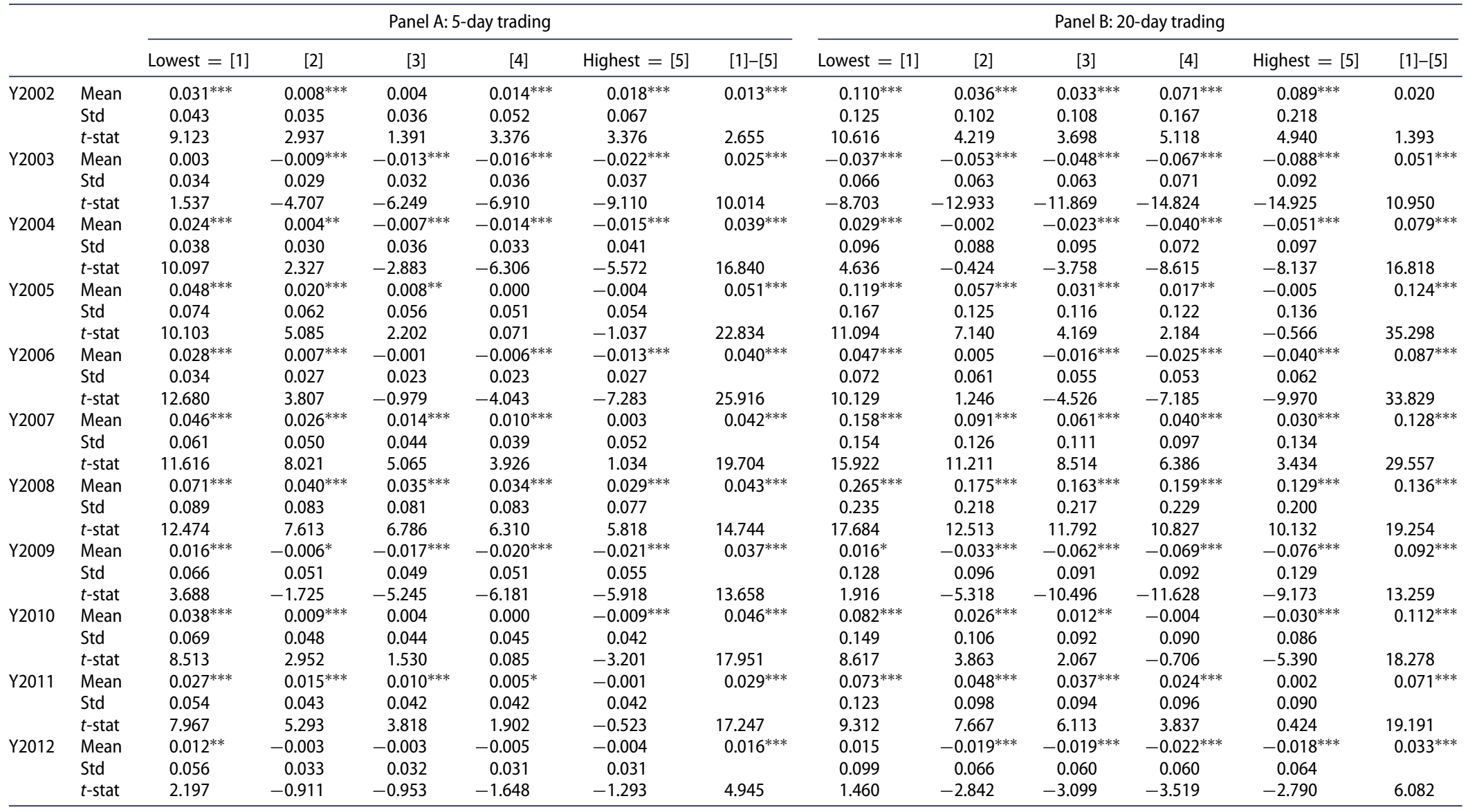

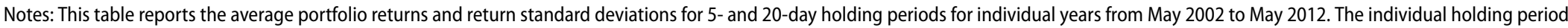

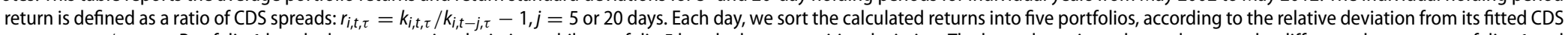

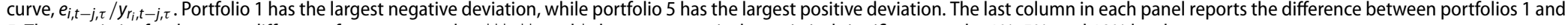

5. The $t$-statistics for the mean difference from zero are also. $* * * * *$, and $*$ denote, respectively, statistical significance at the $1 \%, 5 \%$, and $10 \%$ levels. 
Table A6. Portfolio returns: by CDS maturity.

\begin{tabular}{|c|c|c|c|c|c|c|c|c|c|c|c|c|c|}
\hline & & \multicolumn{6}{|c|}{ Panel A: 5-day trading } & \multicolumn{6}{|c|}{ Panel B: 20-day trading } \\
\hline & & Lowest $=[1]$ & {$[2]$} & [3] & [4] & Highest $=[5]$ & {$[1]-[5]$} & Lowest $=[1]$ & {$[2]$} & [3] & {$[4]$} & Highest $=[5]$ & {$[1]-[5]$} \\
\hline \multirow[t]{3}{*}{ 6-month } & Mean & $0.107^{* * *}$ & $0.044^{* * *}$ & $0.018^{* * *}$ & -0.001 & $-0.016^{* * *}$ & $0.123^{* * *}$ & $0.219^{* * *}$ & $0.101^{* * *}$ & $0.050^{* * *}$ & $0.013^{* *}$ & $-0.026^{* * *}$ & $0.245^{* * *}$ \\
\hline & Std & 0.148 & 0.114 & 0.103 & 0.102 & 0.084 & & 0.305 & 0.255 & 0.251 & 0.229 & 0.209 & \\
\hline & $t$-stat & 33.726 & 18.014 & 7.948 & -0.630 & -8.953 & 43.078 & 32.793 & 18.208 & 9.151 & 2.533 & -5.729 & 52.960 \\
\hline \multirow[t]{3}{*}{ 1-year } & Mean & $0.056^{* * *}$ & $0.027^{* * *}$ & $0.009^{* * *}$ & -0.002 & $-0.009^{* * *}$ & $0.065^{* * *}$ & $0.127^{* * *}$ & $0.066^{* * *}$ & $0.032^{* * *}$ & $0.007^{*}$ & $-0.014^{* * *}$ & $0.141^{* * *}$ \\
\hline & Std & 0.093 & 0.077 & 0.077 & 0.072 & 0.068 & & 0.222 & 0.195 & 0.190 & 0.195 & 0.191 & \\
\hline & $t$-stat & 29.721 & 17.538 & 6.072 & -1.600 & -6.509 & 42.549 & 28.208 & 16.811 & 8.410 & 1.753 & -3.650 & 47.898 \\
\hline \multirow[t]{3}{*}{ 2-year } & Mean & $0.029^{* * *}$ & $0.015^{* * *}$ & $0.005^{* * *}$ & -0.001 & $-0.005^{* * *}$ & $0.034^{* * *}$ & $0.081^{* * *}$ & $0.043^{* * *}$ & $0.022^{* * *}$ & 0.004 & $-0.010^{* * *}$ & $0.091^{* * *}$ \\
\hline & Std & 0.068 & 0.060 & 0.061 & 0.061 & 0.059 & & 0.172 & 0.157 & 0.157 & 0.159 & 0.164 & \\
\hline & $t$-stat & 21.181 & 12.187 & 4.293 & -0.673 & -3.912 & 33.315 & 23.244 & 13.548 & 6.990 & 1.171 & -2.916 & 42.597 \\
\hline \multirow[t]{3}{*}{ 3-year } & Mean & $0.018^{* * *}$ & $0.009^{* * *}$ & $0.004^{* * *}$ & 0.000 & $-0.003^{* *}$ & $0.021 * * *$ & $0.059 * * *$ & $0.030 * * *$ & $0.016^{* * *}$ & $0.007^{* *}$ & $-0.006^{* *}$ & $0.065^{* * *}$ \\
\hline & Std & 0.055 & 0.052 & 0.052 & 0.054 & 0.055 & & 0.140 & 0.134 & 0.133 & 0.145 & 0.148 & \\
\hline & $t$-stat & 16.334 & 8.836 & 3.550 & 0.308 & -2.558 & 25.674 & 20.681 & 11.137 & 6.037 & 2.440 & -2.018 & 34.079 \\
\hline \multirow[t]{3}{*}{ 4-year } & Mean & $0.017^{* * *}$ & $0.010^{* * *}$ & $0.006^{* * *}$ & $0.004^{* * *}$ & 0.001 & $0.016^{* * *}$ & $0.064^{* * *}$ & $0.039^{* * *}$ & $0.027^{* * *}$ & $0.019^{* * *}$ & 0.005 & $0.059^{* * *}$ \\
\hline & Std & 0.054 & 0.050 & 0.050 & 0.052 & 0.053 & & 0.139 & 0.128 & 0.132 & 0.138 & 0.136 & \\
\hline & $t$-stat & 12.647 & 7.818 & 5.016 & 3.260 & 0.652 & 19.995 & 18.634 & 12.145 & 8.191 & 5.462 & 1.491 & 31.254 \\
\hline \multirow[t]{3}{*}{ 5-year } & Mean & $0.013^{* * *}$ & $0.005^{* * *}$ & $0.003^{* * *}$ & $0.002^{*}$ & -0.001 & $0.014^{* * *}$ & $0.047^{* * *}$ & $0.022^{* * *}$ & $0.013^{* * *}$ & $0.008^{* * *}$ & -0.004 & $0.051^{* * *}$ \\
\hline & Std & 0.046 & 0.041 & 0.043 & 0.046 & 0.047 & & 0.117 & 0.106 & 0.107 & 0.120 & 0.125 & \\
\hline & $t$-stat & 14.086 & 6.572 & 3.503 & 1.796 & -1.538 & 21.812 & 19.926 & 10.258 & 6.021 & 3.391 & -1.490 & 31.865 \\
\hline \multirow[t]{3}{*}{ 7-year } & Mean & $0.013^{* * *}$ & $0.006^{* * *}$ & $0.003^{* * *}$ & $0.002^{* *}$ & -0.001 & $0.014^{* * *}$ & $0.044^{* * *}$ & $0.023^{* * *}$ & $0.013^{* * *}$ & $0.011^{* * *}$ & -0.003 & $0.047^{* * *}$ \\
\hline & Std & 0.044 & 0.039 & 0.040 & 0.045 & 0.046 & & 0.107 & 0.098 & 0.100 & 0.118 & 0.122 & \\
\hline & $t$-stat & 14.210 & 7.754 & 3.325 & 2.223 & -1.016 & 20.673 & 20.273 & 11.324 & 6.203 & 4.415 & -1.110 & 32.119 \\
\hline \multirow[t]{3}{*}{ 10-year } & Mean & $0.015^{* * *}$ & $0.007^{* * *}$ & $0.002^{* *}$ & $0.001^{*}$ & -0.001 & $0.016^{* * *}$ & $0.045^{* * *}$ & $0.023^{* * *}$ & $0.011^{* * *}$ & $0.009^{* * *}$ & -0.002 & $0.047^{* * *}$ \\
\hline & Std & 0.043 & 0.038 & 0.038 & 0.043 & 0.047 & & 0.101 & 0.089 & 0.094 & 0.109 & 0.121 & \\
\hline & $t$-stat & 17.906 & 9.710 & 2.265 & 1.652 & -0.955 & 22.058 & 21.949 & 12.634 & 6.049 & 4.046 & -0.910 & 28.778 \\
\hline
\end{tabular}

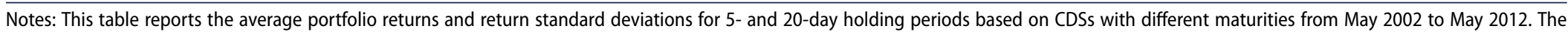

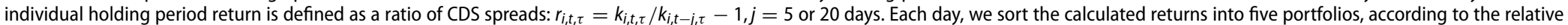

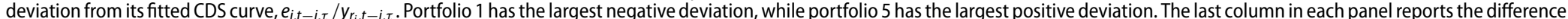
between portfolios 1 and 5 . The $t$-statistics for the mean difference from zero are also reported. ${ }^{* * *}$, $* *$, and $*$ denote, respectively, statistical significance at the $1 \%, 5 \%$, and $10 \%$ levels. 
Table A7. Portfolio returns: by rating.

\begin{tabular}{|c|c|c|c|c|c|c|c|c|c|c|c|c|c|}
\hline & & \multicolumn{6}{|c|}{ Panel A: 5-day trading } & \multicolumn{6}{|c|}{ Panel B: 20-day trading } \\
\hline & & Lowest $=[1]$ & [2] & [3] & [4] & Highest $=[5]$ & [1]-[5] & Lowest $=[1]$ & [2] & [3] & [4] & Highest $=[5]$ & [1]-[5] \\
\hline \multirow[t]{3}{*}{ AAA } & Mean & $0.069^{* * *}$ & $0.025^{* * *}$ & $0.007^{* *}$ & 0.003 & $-0.016^{* * *}$ & $0.084^{* * *}$ & $0.189^{* * *}$ & $0.100^{* * *}$ & $0.039^{* * * *}$ & $0.011^{* *}$ & $-0.022^{* * *}$ & $0.211^{* * *}$ \\
\hline & Std & 0.324 & 0.237 & 0.112 & 0.080 & 0.084 & & 0.649 & 0.486 & 0.243 & 0.179 & 0.177 & \\
\hline & $t$-stat & 8.271 & 4.192 & 2.515 & 1.588 & -7.278 & 10.234 & 10.897 & 7.685 & 6.025 & 2.237 & -4.664 & 12.588 \\
\hline \multirow[t]{3}{*}{ AA } & Mean & $0.046^{* * *}$ & $0.014^{* * *}$ & 0.002 & $-0.008^{* * *}$ & -0.0011 & $0.047^{* * *}$ & $0.111^{* * * *}$ & $0.048^{* * *}$ & $0.014^{* * *}$ & $-0.007^{* *}$ & $0.014^{* * *}$ & $0.097^{* * *}$ \\
\hline & Std & 0.107 & 0.074 & 0.066 & 0.067 & 0.099 & & 0.249 & 0.174 & 0.155 & 0.151 & 0.233 & \\
\hline & $t$-stat & 21.343 & 9.660 & 1.157 & -5.949 & -0.545 & 19.011 & 22.073 & 13.495 & 4.325 & -2.319 & 2.974 & 20.025 \\
\hline \multirow[t]{3}{*}{ A } & Mean & $0.042^{* * *}$ & $0.010^{* * *}$ & 0.001 & -0.001 & $-0.006^{* * *}$ & $0.048^{* * *}$ & $0.095^{* * *}$ & $0.033^{* * *}$ & $0.011^{* * *}$ & $0.008^{* *}$ & $-0.012^{* * *}$ & $0.107^{* * *}$ \\
\hline & Std & 0.077 & 0.062 & 0.058 & 0.061 & 0.064 & & 0.190 & 0.157 & 0.147 & 0.156 & 0.157 & \\
\hline & $t$-stat & 27.365 & 8.264 & 0.962 & -0.958 & -4.561 & 38.851 & 24.523 & 10.453 & 3.798 & 2.426 & -3.918 & 44.281 \\
\hline \multirow[t]{3}{*}{ BBB } & Mean & $0.035^{* * *}$ & $0.009^{* * *}$ & $0.004^{* * *}$ & 0.000 & $-0.005^{* * *}$ & $0.041^{* * *}$ & $0.086^{* * *}$ & $0.031^{\text {*** }}$ & $0.020^{* * * *}$ & $0.006^{* *}$ & $-0.012^{* * *}$ & $0.098^{* * *}$ \\
\hline & Std & 0.069 & 0.055 & 0.053 & 0.055 & 0.057 & & 0.166 & 0.137 & 0.140 & 0.142 & 0.152 & \\
\hline & $t$-stat & 25.534 & 8.249 & 3.284 & 0.370 & -4.654 & 41.705 & 25.485 & 11.339 & 6.882 & 1.982 & -4.040 & 43.631 \\
\hline \multirow[t]{3}{*}{ BB } & Mean & $0.021^{* * *}$ & $0.011^{* * *}$ & $0.004^{* * *}$ & $0.003^{* *}$ & $-0.003^{* *}$ & $0.024^{* * *}$ & $0.057^{* * *}$ & $0.028^{* * *}$ & $0.021^{* * *}$ & $0.012^{* * *}$ & -0.004 & $0.061^{* * *}$ \\
\hline & Std & 0.067 & 0.050 & 0.051 & 0.057 & 0.063 & & 0.150 & 0.120 & 0.142 & 0.174 & 0.165 & \\
\hline & $t$-stat & 15.307 & 11.077 & 3.869 & 2.431 & -2.558 & 15.783 & 18.661 & 11.659 & 7.283 & 3.506 & -1.289 & 19.123 \\
\hline \multirow[t]{3}{*}{ B } & Mean & $0.029^{* * *}$ & $0.008^{* * *}$ & $0.004^{* * *}$ & 0.006 *** & -0.001 & $0.030^{* * *}$ & $0.075^{* * *}$ & $0.033^{* * *}$ & $0.018^{* * *}$ & $0.029^{* * *}$ & 0.004 & $0.071^{* * *}$ \\
\hline & Std & 0.098 & 0.053 & 0.055 & 0.058 & 0.064 & & 0.197 & 0.141 & 0.132 & 0.152 & 0.160 & \\
\hline & $t$-stat & 14.785 & 7.839 & 3.719 & 4.881 & -0.955 & 15.900 & 18.815 & 11.423 & 6.841 & 9.522 & 1.224 & 19.357 \\
\hline \multirow[t]{3}{*}{ C } & Mean & $0.030^{* * *}$ & $0.013^{* * *}$ & $0.010^{* * *}$ & $0.009^{* * *}$ & $0.007^{* *}$ & $0.024^{* * *}$ & $0.082^{* * *}$ & $0.056^{* * *}$ & $0.050^{* * * *}$ & $0.030^{* * *}$ & $0.027^{* * *}$ & $0.055^{* * *}$ \\
\hline & Std & 0.141 & 0.112 & 0.109 & 0.131 & 0.158 & & 0.317 & 0.275 & 0.295 & 0.252 & 0.306 & \\
\hline & $t$-stat & 10.634 & 5.670 & 4.629 & 3.441 & 2.115 & 6.098 & 12.711 & 10.073 & 8.424 & 5.914 & 4.344 & 7.945 \\
\hline
\end{tabular}

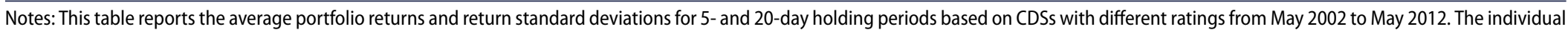

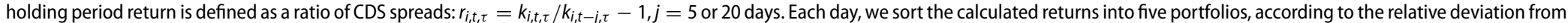

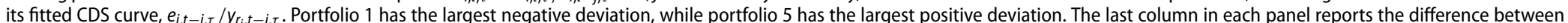
portfolios 1 and 5 . The $t$-statistics for the mean difference from zero are also reported. ${ }^{* * *}$, $* *$, and ${ }^{*}$ denote, respectively, statistical significance at the $1 \%, 5 \%$, and $10 \%$ levels. 
Table A8. Portfolio returns: by industry.

\begin{tabular}{|c|c|c|c|c|c|c|c|c|c|c|c|c|c|}
\hline & & \multicolumn{6}{|c|}{ Panel A: 5-day trading } & \multicolumn{6}{|c|}{ Panel B: 20-day trading } \\
\hline & & Lowest $=[1]$ & [2] & [3] & [4] & Highest $=[5]$ & [1]-[5] & Lowest = [1] & [2] & [3] & [4] & Highest $=[5]$ & {$[1]-[5]$} \\
\hline \multirow[t]{3}{*}{ Basic materials } & Mean & $0.035^{* * *}$ & $0.015^{* * * *}$ & $0.003^{*}$ & -0.002 & $-0.008^{* * *}$ & $0.043^{* * *}$ & $0.084^{* * *}$ & $0.036^{* * *}$ & $0.009^{* * *}$ & -0.002 & $-0.017^{* * *}$ & $0.101^{* * *}$ \\
\hline & Std & 0.089 & 0.069 & 0.066 & 0.065 & 0.062 & & 0.188 & 0.147 & 0.132 & 0.144 & 0.143 & \\
\hline & $t$-stat & 19.675 & 10.545 & 1.901 & -1.438 & -6.024 & 25.874 & 22.207 & 12.258 & 3.429 & -0.572 & -5.748 & 35.448 \\
\hline \multirow[t]{3}{*}{ Consumer goods } & Mean & $0.035^{* * *}$ & $0.011^{* * *}$ & $0.004^{* *}$ & $0.002^{* * *}$ & $-0.005^{* * *}$ & $0.040^{* * *}$ & $0.088^{* * *}$ & $0.036^{* * *}$ & $0.023^{* * *}$ & $0.016^{* * *}$ & $-0.009 * * *$ & $0.098^{* * *}$ \\
\hline & Std & 0.072 & 0.054 & 0.052 & 0.057 & 0.058 & & 0.175 & 0.138 & 0.134 & 0.146 & 0.146 & \\
\hline & $t$-stat & 24.218 & 10.417 & 4.249 & 2.010 & -4.068 & 31.381 & 24.994 & 12.872 & 8.623 & 5.550 & -3.132 & 35.054 \\
\hline \multirow[t]{3}{*}{ Consumer services } & Mean & $0.029^{* * *}$ & $0.013^{* * *}$ & $0.005^{* * *}$ & $0.002^{*}$ & $-0.005^{* * *}$ & $0.033^{* * *}$ & $0.073^{* * *}$ & $0.039^{* * *}$ & $0.021^{* * *}$ & $0.010^{* * *}$ & $-0.008^{* * *}$ & $0.080^{* * *}$ \\
\hline & Std & 0.071 & 0.059 & 0.059 & 0.059 & 0.056 & & 0.170 & 0.151 & 0.143 & 0.146 & 0.146 & \\
\hline & $t$-stat & 19.959 & 10.775 & 4.403 & 1.945 & -4.271 & 29.571 & 21.075 & 12.747 & 7.307 & 3.459 & -2.591 & 34.984 \\
\hline \multirow[t]{3}{*}{ Energy } & Mean & $0.032^{* * *}$ & $0.011^{\text {*** }}$ & 0.002 & 0.000 & $-0.005^{* * *}$ & $0.037^{* * *}$ & $0.075^{* * *}$ & $0.032^{* * *}$ & $0.013^{* * *}$ & $0.009^{* *}$ & -0.002 & $0.077^{* * *}$ \\
\hline & Std & 0.087 & 0.068 & 0.062 & 0.067 & 0.080 & & 0.206 & 0.166 & 0.162 & 0.176 & 0.219 & \\
\hline & $t$-stat & 18.571 & 8.364 & 1.402 & 0.048 & -3.068 & 24.417 & 18.089 & 9.494 & 3.957 & 2.473 & -0.444 & 20.973 \\
\hline \multirow[t]{3}{*}{ Financials } & Mean & $0.025^{* * *}$ & $0.020^{* * *}$ & $0.013^{* * *}$ & 0.000 & $0.005^{*}$ & $0.020^{* * *}$ & $0.063^{* * *}$ & $0.058^{* * *}$ & $0.035^{* * *}$ & $0.013^{* * *}$ & $0.036^{* * *}$ & $0.026^{* * *}$ \\
\hline & Std & 0.137 & 0.124 & 0.114 & 0.104 & 0.130 & & 0.273 & 0.251 & 0.251 & 0.237 & 0.336 & \\
\hline & $t$-stat & 9.014 & 8.204 & 5.560 & 0.110 & 1.722 & 6.166 & 11.336 & 11.417 & 6.924 & 2.699 & 5.351 & 3.641 \\
\hline \multirow[t]{3}{*}{ Healthcare } & Mean & $0.028^{* * *}$ & $0.011^{* * *}$ & $0.003^{* *}$ & 0.000 & $-0.007^{* * *}$ & $0.035^{* * *}$ & $0.077^{* * *}$ & $0.032^{* * *}$ & $0.012^{* * *}$ & 0.000 & $-0.016^{* * *}$ & $0.093^{* * *}$ \\
\hline & Std & 0.079 & 0.064 & 0.065 & 0.072 & 0.056 & & 0.188 & 0.150 & 0.139 & 0.145 & 0.134 & \\
\hline & $t$-stat & 17.511 & 8.596 & 2.204 & -0.077 & -6.283 & 21.877 & 19.925 & 10.274 & 4.048 & 0.047 & -5.869 & 27.671 \\
\hline \multirow[t]{3}{*}{ Industrials } & Mean & $0.036^{* * *}$ & $0.011^{* * *}$ & $0.003^{* * *}$ & $-0.002^{* *}$ & $-0.005^{* * *}$ & $0.041^{* * *}$ & $0.078^{* * *}$ & $0.034^{* * *}$ & $0.014^{* * *}$ & 0.001 & $-0.008^{* * *}$ & $0.086^{* * *}$ \\
\hline & Std & 0.088 & 0.060 & 0.053 & 0.053 & 0.056 & & 0.194 & 0.150 & 0.133 & 0.131 & 0.135 & \\
\hline & $t$-stat & 20.302 & 9.048 & 2.974 & -2.080 & -4.234 & 28.717 & 19.935 & 11.321 & 5.238 & 0.450 & -2.923 & 32.450 \\
\hline \multirow[t]{3}{*}{ Technology } & Mean & $0.033^{* * *}$ & $0.008^{* * *}$ & $0.006^{* * *}$ & 0.002 & $-0.008^{* * *}$ & $0.041^{* * *}$ & $0.087^{* * *}$ & $0.028^{* * *}$ & $0.030^{* * *}$ & $0.007^{* *}$ & $-0.022^{* * *}$ & $0.109 * * *$ \\
\hline & Std & 0.084 & 0.061 & 0.071 & 0.062 & 0.063 & & 0.207 & 0.153 & 0.192 & 0.161 & 0.162 & \\
\hline & $t$-stat & 19.467 & 6.511 & 4.294 & 1.314 & -6.400 & 25.102 & 20.761 & 9.161 & 7.774 & 2.169 & -6.600 & 30.307 \\
\hline Telecommunications & Mean & $0.028^{* * *}$ & $0.008^{* * *}$ & $0.004^{* * *}$ & 0.002 & $-0.005^{* * *}$ & $0.033^{* * *}$ & $0.063^{* * *}$ & $0.025^{* * *}$ & $0.013^{* * *}$ & $0.007^{* *}$ & $-0.009^{* *}$ & $0.072^{* * *}$ \\
\hline \multirow{2}{*}{ services } & Std & 0.093 & 0.074 & 0.066 & 0.079 & 0.082 & & 0.211 & 0.146 & 0.147 & 0.159 & 0.178 & \\
\hline & $t$-stat & 13.877 & 5.142 & 2.875 & 0.922 & -2.784 & 13.651 & 13.502 & 7.754 & 4.037 & 2.008 & -2.334 & 15.721 \\
\hline \multirow[t]{3}{*}{ Utilities } & Mean & $0.036^{* * *}$ & $0.011^{* * *}$ & $0.007^{* * *}$ & 0.000 & -0.003 & $0.039^{* * *}$ & $0.086^{* * *}$ & $0.038^{* * *}$ & $0.034^{* * *}$ & $0.009^{* *}$ & -0.002 & $0.088^{* * *}$ \\
\hline & Std & 0.106 & 0.083 & 0.081 & 0.080 & 0.101 & & 0.246 & 0.214 & 0.228 & 0.207 & 0.243 & \\
\hline & $t$-stat & 16.623 & 6.757 & 4.327 & 0.147 & -1.415 & 18.525 & 17.308 & 8.809 & 7.475 & 2.062 & -0.329 & 19.408 \\
\hline
\end{tabular}

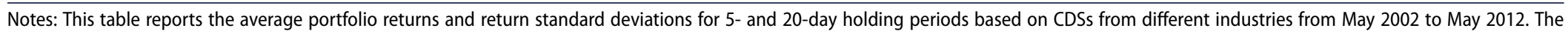

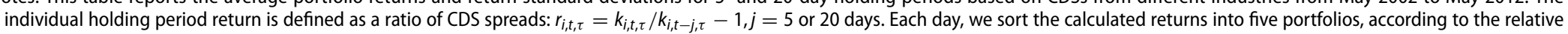

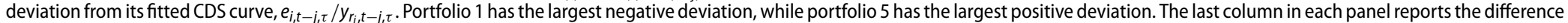

between portfolios 1 and 5 . The $t$-statistics for the mean difference from zero are also reported. $* * * * *$, and $*$ denote, respectively, statistical significance at the $1 \%, 5 \%$, and $10 \%$ levels. 
Table A9. Transaction cost adjusted portfolio returns: year by year.

\begin{tabular}{|c|c|c|c|c|c|c|c|}
\hline & & \multicolumn{3}{|c|}{ Panel A: 5-day trading } & \multicolumn{3}{|c|}{ Panel B: 20-day trading } \\
\hline & & Lowest $=[1]$ & Highest $=[5]$ & [1]-[5] & Lowest $=[1]$ & Highest $=[5]$ & {$[1]-[5]$} \\
\hline \multirow[t]{3}{*}{ Y2002 } & Mean & $0.018^{* * *}$ & $0.028^{* * *}$ & $-0.010^{* *}$ & $0.096^{* * *}$ & $0.10^{* * *}$ & -0.003 \\
\hline & Std & 0.042 & 0.068 & & 0.123 & 0.220 & \\
\hline & $t$-stat & 5.465 & 5.195 & -2.013 & 9.452 & 5.467 & -0.216 \\
\hline \multirow[t]{3}{*}{ Y2003 } & Mean & $-0.008^{* * *}$ & $-0.012^{* * *}$ & $0.004^{*}$ & $-0.047^{* * *}$ & $-0.079^{* * *}$ & $0.032^{* * *}$ \\
\hline & Std & 0.034 & 0.037 & & 0.065 & 0.093 & \\
\hline & $t$-stat & -3.661 & -5.090 & 1.719 & -11.386 & -13.350 & 6.769 \\
\hline \multirow[t]{3}{*}{ Y2004 } & Mean & $0.010^{* * *}$ & -0.003 & $0.013^{* * *}$ & $0.016^{* *}$ & $-0.040^{* * *}$ & $0.055^{* * *}$ \\
\hline & Std & 0.037 & 0.042 & & 0.095 & 0.099 & \\
\hline & $t$-stat & 4.329 & -1.020 & 5.611 & 2.537 & -6.238 & 11.616 \\
\hline \multirow[t]{3}{*}{ Y2005 } & Mean & $0.029^{* * *}$ & $0.009^{* *}$ & $0.020^{* * *}$ & $0.099^{* * *}$ & 0.007 & $0.092^{* * *}$ \\
\hline & Std & 0.072 & 0.055 & & 0.164 & 0.138 & \\
\hline & $t$-stat & 6.287 & 2.577 & 9.209 & 9.447 & 0.810 & 27.582 \\
\hline \multirow[t]{3}{*}{ Y2006 } & Mean & $0.010^{* * *}$ & -0.001 & $0.010^{* * *}$ & $0.029^{* * *}$ & $-0.029^{* * *}$ & $0.057^{* * *}$ \\
\hline & Std & 0.034 & 0.027 & & 0.071 & 0.062 & \\
\hline & $t$-stat & 4.530 & -0.329 & 6.713 & 6.300 & -7.088 & 22.634 \\
\hline \multirow[t]{3}{*}{ Y2007 } & Mean & $0.028^{* * *}$ & $0.015^{* * *}$ & $0.013^{* * *}$ & $0.138^{* * *}$ & $0.041^{* * *}$ & $0.097^{* * *}$ \\
\hline & Std & 0.060 & 0.053 & & 0.150 & 0.136 & \\
\hline & $t$-stat & 7.264 & 4.369 & 6.200 & 14.266 & 4.716 & 23.048 \\
\hline \multirow[t]{3}{*}{ Y2008 } & Mean & $0.051^{* * *}$ & $0.041^{* * *}$ & $0.010^{* * *}$ & $0.241^{* * *}$ & $0.143^{* * *}$ & $0.098^{* * *}$ \\
\hline & Std & 0.088 & 0.078 & & 0.230 & 0.202 & \\
\hline & $t$-stat & 9.097 & 8.189 & 3.637 & 16.408 & 11.035 & 14.281 \\
\hline \multirow[t]{3}{*}{ Y2009 } & Mean & -0.000 & $-0.009^{* *}$ & $0.009^{* * *}$ & 0.000 & $-0.065^{* * *}$ & $0.066^{* * *}$ \\
\hline & Std & 0.065 & 0.056 & & 0.126 & 0.131 & \\
\hline & $t$-stat & -0.086 & -2.571 & 3.313 & 0.055 & -7.757 & 9.417 \\
\hline \multirow[t]{3}{*}{ Y2010 } & Mean & $0.020^{* * *}$ & 0.003 & $0.017^{* * *}$ & $0.064^{* * *}$ & $-0.019^{* * *}$ & $0.084^{* * *}$ \\
\hline & Std & 0.067 & 0.042 & & 0.146 & 0.087 & \\
\hline & $t$-stat & 4.603 & 0.932 & 6.977 & 6.870 & -3.455 & 13.969 \\
\hline \multirow[t]{3}{*}{ Y2011 } & Mean & $0.010^{* * *}$ & $0.010^{* * *}$ & 0.001 & $0.056^{* * *}$ & $0.013^{* *}$ & $0.042^{* * *}$ \\
\hline & Std & 0.052 & 0.043 & & 0.120 & 0.091 & \\
\hline & $t$-stat & 3.128 & 3.556 & 0.455 & 7.236 & 2.270 & 11.887 \\
\hline \multirow[t]{3}{*}{ Y2012 } & Mean & -0.006 & $0.008^{* *}$ & $-0.014^{* * *}$ & -0.004 & -0.007 & 0.003 \\
\hline & Std & 0.054 & 0.031 & & 0.097 & 0.065 & \\
\hline & $t$-stat & -1.097 & 2.567 & -4.480 & -0.379 & -0.986 & 0.543 \\
\hline
\end{tabular}

Notes: This table reports the average portfolio returns and return standard deviations for 5 - and 20-day holding periods for individual years from

May 2002 to May 2012. The individual holding period return is defined as a ratio of transaction costs adjusted CDS spreads: $\tilde{r}_{i, t, \tau}=\tilde{k}_{i, t, \tau} / \tilde{k}_{i, t-j, \tau}-$ $1, j=5$ or 20 days. Each day, we sort the calculated returns into five portfolios, according to the relative deviation from its fitted CDS curve, $e_{i, t-j, \tau} / y_{r_{i}, t-j, \tau}$. Portfolio 1 has the largest negative deviation, while portfolio 5 has the largest positive deviation. The last column in each panel reports the difference between portfolios 1 and 5 . The $t$-statistics for the mean difference from zero are also. $* * *, * *$, and * denote, respectively, statistical significance at the $1 \%, 5 \%$, and $10 \%$ levels.

into quintiles, and report the performance of portfolio 1 (with the largest negative deviations) and portfolio 5 (with the largest positive deviations). We do not report the transaction costs adjusted performance of portfolios 2 to 4 , as the trading direction in these portfolios may not be stable. The portfolio returns are reported for 5-day and 20-day holding periods. 
Table A10. Transaction cost adjusted portfolio returns: by CDS maturity.

\begin{tabular}{|c|c|c|c|c|c|c|c|}
\hline & & \multicolumn{3}{|c|}{ Panel A: 5-day trading } & \multicolumn{3}{|c|}{ Panel B: 20-day trading } \\
\hline & & Lowest $=[1]$ & Highest $=[5]$ & [1]-[5] & Lowest $=[1]$ & Highest $=[5]$ & [1]-[5] \\
\hline \multirow[t]{3}{*}{ 6-month } & Mean & $0.053^{* * *}$ & $0.034^{* * *}$ & $0.019 * * *$ & $0.159^{* * *}$ & $0.024^{* * *}$ & $0.136^{* * *}$ \\
\hline & Std & 0.141 & 0.089 & & 0.290 & 0.220 & \\
\hline & $t$-stat & 17.578 & 18.022 & 6.844 & 25.106 & 4.939 & 30.813 \\
\hline \multirow[t]{3}{*}{ 1-year } & Mean & $0.030^{* * *}$ & $0.016^{* * *}$ & $0.014^{* * *}$ & $0.099^{* * *}$ & $0.011^{* * *}$ & $0.088^{* * *}$ \\
\hline & Std & 0.091 & 0.070 & & 0.216 & 0.196 & \\
\hline & $t$-stat & 16.277 & 11.362 & 9.187 & 22.573 & 2.737 & 30.332 \\
\hline \multirow[t]{3}{*}{ 2-year } & Mean & $0.016^{* * *}$ & $0.008^{* * *}$ & $0.008 * * *$ & $0.068^{* * *}$ & 0.003 & $0.065^{* * *}$ \\
\hline & Std & 0.067 & 0.060 & & 0.170 & 0.166 & \\
\hline & $t$-stat & 11.956 & 6.451 & 8.246 & 19.637 & 0.831 & 30.514 \\
\hline \multirow[t]{3}{*}{ 3-year } & Mean & $0.010^{* * *}$ & $0.005^{* * *}$ & $0.004^{* * *}$ & $0.050^{* * *}$ & 0.002 & $0.047^{* * *}$ \\
\hline & Std & 0.055 & 0.056 & & 0.139 & 0.149 & \\
\hline & $t$-stat & 8.825 & 4.869 & 5.200 & 17.725 & 0.747 & 24.991 \\
\hline \multirow[t]{3}{*}{ 4-year } & Mean & $0.011^{* * *}$ & $0.007^{* * *}$ & $0.003^{* * *}$ & $0.058^{* * *}$ & $0.011^{* * *}$ & $0.046^{* * *}$ \\
\hline & Std & 0.054 & 0.053 & & 0.138 & 0.137 & \\
\hline & $t$-stat & 7.969 & 5.384 & 4.326 & 16.821 & 3.322 & 24.457 \\
\hline \multirow[t]{3}{*}{ 5-year } & Mean & $0.008^{* * *}$ & $0.004^{* * *}$ & $0.004^{* * *}$ & $0.042^{* * *}$ & 0.001 & $0.041^{* * *}$ \\
\hline & Std & 0.045 & 0.047 & & 0.116 & 0.126 & \\
\hline & $t$-stat & 8.634 & 3.741 & 6.579 & 17.807 & 0.472 & 25.426 \\
\hline \multirow[t]{3}{*}{ 7-year } & Mean & $0.009^{* * *}$ & $0.003^{* * *}$ & $0.006^{* * *}$ & $0.040^{* * *}$ & 0.001 & $0.039 * * *$ \\
\hline & Std & 0.044 & 0.046 & & 0.106 & 0.122 & \\
\hline & $t$-stat & 10.197 & 2.822 & 9.755 & 18.616 & 0.335 & 27.018 \\
\hline \multirow[t]{3}{*}{ 10-year } & Mean & $0.013^{* * *}$ & $0.002^{*}$ & $0.011^{* * *}$ & $0.042^{* * *}$ & 0.000 & $0.042^{* * *}$ \\
\hline & Std & 0.043 & 0.047 & & 0.100 & 0.122 & \\
\hline & $t$-stat & 15.004 & 1.664 & 15.254 & 20.722 & 0.107 & 25.607 \\
\hline
\end{tabular}

Notes: This table reports the average portfolio returns and return standard deviations for 5- and 20-day holding periods based on CDSs with different maturities from May 2002 to May 2012. The individual holding period return is defined as a ratio of transaction costs adjusted CDS spreads: $\tilde{r}_{i, t, \tau}=\tilde{k}_{i, t, \tau} / \tilde{k}_{i, t-j, \tau}-1, j=5$ or 20 days. Each day, we sort the calculated returns into five portfolios, according to the relative deviation from its fitted CDS curve, $e_{i, t-j, \tau} / y_{r_{i}, t-j, \tau}$. Portfolio 1 has the largest negative deviation, while portfolio 5 has the largest positive deviation. The last column in each panel reports the difference between portfolios 1 and 5 . The $t$-statistics for the mean difference from zero are also reported. $* * *, * *$, and $*$ denote, respectively, statistical significance at the $1 \%, 5 \%$, and $10 \%$ levels. 
Table A11. Transaction cost adjusted portfolio returns: by rating.

\begin{tabular}{|c|c|c|c|c|c|c|c|}
\hline & & \multicolumn{3}{|c|}{ Panel A: 5-day trading } & \multicolumn{3}{|c|}{ Panel B: 20-day trading } \\
\hline & & Lowest $=[1]$ & Highest $=[5]$ & {$[1]-[5]$} & Lowest $=[1]$ & Highest $=[5]$ & [1]-[5] \\
\hline \multirow[t]{3}{*}{ AAA } & Mean & $0.052^{* * *}$ & -0.003 & $0.056^{* * *}$ & $0.171^{* * *}$ & $-0.010^{* *}$ & $0.182^{* * *}$ \\
\hline & Std & 0.320 & 0.085 & & 0.644 & 0.178 & \\
\hline & $t$-stat & 6.377 & -1.547 & 6.838 & 9.993 & -2.183 & 10.969 \\
\hline \multirow[t]{3}{*}{ AA } & Mean & $0.028^{* * *}$ & $0.011^{* * *}$ & $0.017^{* * *}$ & $0.091^{* * *}$ & $0.026^{* * *}$ & $0.065^{* * *}$ \\
\hline & Std & 0.104 & 0.101 & & 0.241 & 0.237 & \\
\hline & $t$-stat & 13.097 & 5.345 & 6.713 & 18.742 & 5.432 & 13.510 \\
\hline \multirow[t]{3}{*}{ A } & Mean & $0.024 * * *$ & $0.005^{* * *}$ & $0.019^{* * *}$ & $0.075^{* * *}$ & -0.002 & $0.077^{* * *}$ \\
\hline & Std & 0.075 & 0.065 & & 0.185 & 0.159 & \\
\hline & $t$-stat & 15.880 & 3.861 & 15.370 & 20.070 & -0.554 & 32.507 \\
\hline \multirow[t]{3}{*}{ BBB } & Mean & $0.018^{* * *}$ & $0.006^{* * *}$ & $0.012^{* * *}$ & $0.068^{* * *}$ & -0.001 & $0.069^{* * *}$ \\
\hline & Std & 0.067 & 0.058 & & 0.162 & 0.154 & \\
\hline & $t$-stat & 13.523 & 5.230 & 12.703 & 20.681 & -0.420 & 31.159 \\
\hline \multirow[t]{3}{*}{ BB } & Mean & $0.006^{* * *}$ & $0.009^{* * *}$ & -0.002 & $0.042^{* * *}$ & $0.007^{* *}$ & $0.035^{* * *}$ \\
\hline & Std & 0.065 & 0.063 & & 0.147 & 0.168 & \\
\hline & $t$-stat & 4.868 & 6.941 & -1.640 & 14.125 & 2.207 & 10.831 \\
\hline \multirow[t]{3}{*}{ B } & Mean & $0.012^{* * *}$ & $0.009^{* * *}$ & $0.003^{*}$ & $0.058^{* * *}$ & $0.014^{* * *}$ & $0.044^{* * *}$ \\
\hline & Std & 0.096 & 0.064 & & 0.192 & 0.162 & \\
\hline & $t$-stat & 6.423 & 7.024 & 1.726 & 14.853 & 4.308 & 12.062 \\
\hline \multirow[t]{3}{*}{ C } & Mean & $0.011^{* * *}$ & $0.016^{* * *}$ & -0.005 & $0.062^{* * *}$ & $0.035^{* * *}$ & $0.026^{* * *}$ \\
\hline & Std & 0.138 & 0.159 & & 0.311 & 0.309 & \\
\hline & $t$-stat & 3.932 & 4.904 & -1.247 & 9.810 & 5.671 & 3.853 \\
\hline
\end{tabular}

Notes: This table reports the average portfolio returns and return standard deviations for 5- and 20-day holding periods based on CDSs with different ratings from May 2002 to May 2012. The individual holding period return is defined as a ratio of transaction costs adjusted CDS spreads: $\tilde{r}_{i, t, \tau}=\tilde{k}_{i, t, \tau} / \tilde{k}_{i, t-j, \tau}-1, j=5$ or 20 days. Each day, we sort the calculated returns into five portfolios, according to the relative deviation from its fitted CDS curve, $e_{i, t-j, \tau} / y_{r_{i}, t-j, \tau}$. Portfolio 1 has the largest negative deviation, while portfolio 5 has the largest positive deviation. The last column in each panel reports the difference between portfolios 1 and 5 . The $t$-statistics for the mean difference from zero are also reported. $* * *$, **, and * denote, respectively, statistical significance at the $1 \%, 5 \%$, and $10 \%$ levels.

Table A12. Transaction cost adjusted portfolio returns: by industry.

\begin{tabular}{|c|c|c|c|c|c|c|c|}
\hline & & \multicolumn{3}{|c|}{ Panel A: 5-day trading } & \multicolumn{3}{|c|}{ Panel B: 20-day trading } \\
\hline & & Lowest $=[1]$ & Highest $=[5]$ & {$[1]-[5]$} & Lowest $=[1]$ & Highest $=[5]$ & [1]-[5] \\
\hline \multirow[t]{3}{*}{ Basic materials } & Mean & $0.018^{* * *}$ & $0.004^{* * *}$ & $0.014 * * *$ & $0.066^{* * *}$ & $-0.006^{* *}$ & $0.073^{* * *}$ \\
\hline & Std & 0.087 & 0.063 & & 0.183 & 0.145 & \\
\hline & $t$-stat & 10.150 & 2.754 & 8.710 & 17.884 & -2.088 & 25.753 \\
\hline \multirow[t]{3}{*}{ Consumer goods } & Mean & $0.018^{* * *}$ & $0.007^{* * *}$ & $0.012^{* * *}$ & $0.071^{* * *}$ & 0.002 & $0.069^{* * *}$ \\
\hline & Std & 0.070 & 0.059 & & 0.171 & 0.148 & \\
\hline & $t$-stat & 12.865 & 5.504 & 9.234 & 20.511 & 0.614 & 25.062 \\
\hline \multirow[t]{3}{*}{ Consumer services } & Mean & $0.013^{* * *}$ & $0.006^{* * *}$ & $0.007^{* * *}$ & $0.056^{* * *}$ & 0.003 & $0.053^{* * *}$ \\
\hline & Std & 0.069 & 0.057 & & 0.166 & 0.148 & \\
\hline & $t$-stat & 9.023 & 4.951 & 6.212 & 16.627 & 0.883 & 23.602 \\
\hline \multirow[t]{3}{*}{ Energy } & Mean & $0.015^{* * *}$ & $0.006^{* * *}$ & $0.009^{* * *}$ & $0.057^{* * *}$ & $0.009^{* *}$ & $0.048^{* * *}$ \\
\hline & Std & 0.084 & 0.081 & & 0.200 & 0.221 & \\
\hline & $t$-stat & 8.853 & 3.712 & 5.925 & 14.084 & 1.976 & 13.189 \\
\hline \multirow[t]{3}{*}{ Financials } & Mean & $0.009^{* * *}$ & $0.017^{* * *}$ & $-0.008^{* *}$ & $0.046^{* * *}$ & $0.049^{* * *}$ & -0.002 \\
\hline & Std & 0.134 & 0.132 & & 0.268 & 0.342 & \\
\hline & $t$-stat & 3.284 & 6.217 & -2.328 & 8.528 & 7.021 & -0.310 \\
\hline \multirow[t]{3}{*}{ Healthcare } & Mean & $0.013^{* * *}$ & $0.004^{* * *}$ & $0.009^{* * *}$ & $0.061^{* * *}$ & $-0.005^{*}$ & $0.066^{* * *}$ \\
\hline & Std & 0.077 & 0.057 & & 0.185 & 0.136 & \\
\hline & $t$-stat & 8.071 & 3.545 & 5.364 & 16.049 & -1.860 & 19.839 \\
\hline \multirow[t]{3}{*}{ Industrials } & Mean & $0.018^{* * *}$ & $0.006^{* * *}$ & $0.012^{* * *}$ & $0.060^{* * *}$ & 0.003 & $0.058^{* * *}$ \\
\hline & Std & 0.086 & 0.057 & & 0.190 & 0.137 & \\
\hline & $t$-stat & 10.627 & 5.661 & 8.575 & 15.698 & 1.020 & 22.069 \\
\hline \multirow[t]{3}{*}{ Technology } & Mean & $0.017^{* * *}$ & $0.003^{* * *}$ & $0.014^{* * *}$ & $0.071^{* * *}$ & $-0.011^{* * *}$ & $0.081^{* * *}$ \\
\hline & Std & 0.082 & 0.064 & & 0.202 & 0.164 & \\
\hline & $t$-stat & 10.462 & 2.570 & 8.647 & 17.291 & -3.187 & 23.038 \\
\hline
\end{tabular}


Table A12. Continued.

\begin{tabular}{|c|c|c|c|c|c|c|c|}
\hline & & \multicolumn{3}{|c|}{ Panel A: 5-day trading } & \multicolumn{3}{|c|}{ Panel B: 20-day trading } \\
\hline & & Lowest $=[1]$ & Highest $=[5]$ & {$[1]-[5]$} & Lowest $=[1]$ & Highest $=[5]$ & {$[1]-[5]$} \\
\hline \multirow{3}{*}{$\begin{array}{l}\text { Telecommunications } \\
\text { services }\end{array}$} & Mean & $0.012^{* * *}$ & $0.006^{* * *}$ & $0.006^{* *}$ & $0.045^{* * *}$ & 0.001 & $0.045^{* * *}$ \\
\hline & Std & 0.090 & 0.083 & & 0.203 & 0.179 & \\
\hline & $t$-stat & 5.865 & 3.032 & 2.514 & 10.121 & 0.200 & 9.881 \\
\hline \multirow[t]{3}{*}{ Utilities } & Mean & $0.019^{* * *}$ & $0.009 * * *$ & $0.010^{* * *}$ & $0.068^{* * *}$ & $0.010^{* *}$ & $0.058^{* * *}$ \\
\hline & Std & 0.104 & 0.102 & & 0.240 & 0.246 & \\
\hline & $t$-stat & 8.874 & 4.408 & 4.614 & 14.026 & 2.002 & 12.996 \\
\hline
\end{tabular}

Notes: This table reports the average portfolio returns and return standard deviations for 5- and 20-day holding periods based on CDSs from different industries from May 2002 to May 2012. The individual holding period return is defined as a ratio of transaction costs adjusted CDS spreads: $\tilde{r}_{i, t, \tau}=\tilde{k}_{i, t, \tau} / \tilde{k}_{i, t-j, \tau}-1, j=5$ or 20 days. Each day, we sort the calculated returns into five portfolios, according to the relative deviation from its fitted CDS curve, $e_{i, t-j, \tau} / y_{r_{i}, t-j, \tau}$. Portfolio 1 has the largest negative deviation, while portfolio 5 has the largest positive deviation. The last column in each panel reports the difference between portfolios 1 and 5 . The $t$-statistics for the mean difference from zero are also reported. $* * *, * *$, and $*$ denote, respectively, statistical significance at the $1 \%, 5 \%$, and $10 \%$ levels. 